\title{
Secreted Ectodomain of Sialic Acid-Binding Ig-Like Lectin-9 and Monocyte Chemoattractant Protein-1 Promote Recovery after Rat Spinal Cord Injury by Altering Macrophage Polarity
}

\author{
Kohki Matsubara, ${ }^{1}$ ○Yoshihiro Matsushita, ${ }^{1}$ Kiyoshi Sakai, ${ }^{1}$ Fumiya Kano, ${ }^{1}$ Megumi Kondo, ${ }^{1}{ }^{\oplus}$ Mariko Noda, ${ }^{4}$ \\ Noboru Hashimoto, ${ }^{3}$ Shiro Imagama, ${ }^{2}$ Naoki Ishiguro, ${ }^{2}$ Akio Suzumura, ${ }^{4}$ Minoru Ueda, ${ }^{1}$ Koichi Furukawa, ${ }^{3}$ \\ and Akihito Yamamoto ${ }^{1}$ \\ ${ }^{1}$ Department of Oral and Maxillofacial Surgery, ${ }^{2}$ Orthopedic Surgery, and ${ }^{3}$ Biochemistry II, Nagoya University Graduate School of Medicine, Showa-ku, \\ Nagoya 466-8550, Japan, and ${ }^{4}$ Department of Neuroimmunology, Research Institute of Environmental Medicine, Nagoya University, Chikusa-ku, Nagoya \\ 464-8601, Japan
}

Engrafted mesenchymal stem cells from human deciduous dental pulp (SHEDs) support recovery from neural insults via paracrine mechanisms that are poorly understood. Here we show that the conditioned serum-free medium (CM) from SHEDs, administered intrathecally into rat injured spinal cord during the acute postinjury period, caused remarkable functional recovery. The ability of SHED-CM to induce recovery was associated with an immunoregulatory activity that induced anti-inflammatory M2-like macrophages. Secretome analysis of the SHED-CM revealed a previously unrecognized set of inducers for anti-inflammatory M2-like macrophages: monocyte chemoattractant protein-1 (MCP-1) and the secreted ectodomain of sialic acid-binding Ig-like lectin-9(ED-Siglec-9). Depleting MCP-1 and ED-Siglec-9 from the SHED-CM prominently reduced its ability to induce M2-like macrophages and to promote functional recovery after spinal cord injury (SCI). The combination of MCP-1 and ED-Siglec-9 synergistically promoted the M2-like differentiation of bone marrow-derived macrophages in vitro, and this effect was abolished by a selective antagonist for CC chemokine receptor 2 (CCR2) or by the genetic knock-out of CCR2. Furthermore, MCP-1 and ED-Siglec-9 administration into the injured spinal cord induced M2-like macrophages and led to a marked recovery of hindlimb locomotor function after SCI. The inhibition of this M2 induction through the inactivation of CCR2 function abolished the therapeutic effects of both SHED-CM and MCP-1/ED-Siglec-9. Macrophages activated by MCP-1 and ED-Siglec-9 extended neurite and suppressed apoptosis of primary cerebellar granule neurons against the neurotoxic effects of chondroitin sulfate proteoglycans. Our data suggest that the unique combination of MCP-1 and ED-Siglec-9 repairs the SCI through anti-inflammatory M2-like macrophage induction.

Key words: anti-inflammation; dental pulp stem cells; macrophage polarity; MCP-1; Siglec-9; spinal cord injury

\section{Introduction}

Severe inflammation hinders functional recovery after spinal cord injury (SCI). It has been shown that divergent activation states of monocyte/macrophage lineages play central roles in the pathophysiology of SCI (Kigerl et al., 2009; Shechter et al., 2009; David and Kroner, 2011; Shin et al., 2013). The proinflammatory

Received Oct. 3, 2014; revised Dec. 6, 2014; accepted Dec. 21, 2014.

Author contributions: K.M. and A.Y. designed research; K.M., Y.M., K.S., F.K., M.K., M.N., N.H., S.I, N.I., A.S., M.U., and K.F. performed research; K.M. analyzed data; K.M. and A.Y. wrote the paper.

This work was supported by Grants-in-Aid for Scientific Research on Priority Areas from the Ministry of Education, Culture, Sports, Science, and Technology of Japan and Grants-in-Aid for the Practical Application of Regenerative Medicine from the Ministry of Health, Labour, and Welfare of Japan.

The authors declare no competing financial interests.

We are grateful to M. Takahashi, G. Sobue, K. Kadomatsu, M. Hibi (Nagoya University), and T. Isa (National Institute of Physiological Science) for their critical reading of this manuscript. We also thank the Division of Experimental Animals and Medical Research Engineering, Nagoya University Graduate School of Medicine, for housing the animals and for microscope maintenance.

Correspondence should be addressed to Akihito Yamamoto, Department of Oral and Maxillofacial Surgery, 65 Tsurumai-cho, Showa-ku, Nagoya 466-8550, Japan. E-mail: akihito@med.nagoya-u.ac.jp.

DOI:10.1523/JNEUROSCI.4088-14.2015

Copyright $\odot 2015$ the authors $\quad 0270-6474 / 15 / 352452-13 \$ 15.00 / 0$
M1-type cells and anti-inflammatory M2-type cells are thought to represent the extreme activation states on each end of a continuum (Gordon and Martinez, 2010; Mantovani et al., 2013; Murray et al., 2014). Because activated microglia and macrophages cannot be distinguished by their morphology or expression of antigenic markers, they are here referred to as microglia/ macrophages. M1-like cells initiate inflammation by releasing high levels of proinflammatory cytokines, glutamate, reactive oxygen species, and nitric oxide. These neurotoxic factors accelerate glial scar formation (Fitch et al., 1999), neuronal cell death (Colton and Gilbert, 1987), and the retraction of damaged dystrophic axons (Horn et al., 2008). M1-like cells also play important roles in cell debris clearance and in the recruitment and activation of astrocytes, activities that prepare the space for tissue regeneration. In contrast, M2-like cells counteract the proinflammatory M1 conditions and promote tissue repair by secreting antiinflammatory cytokines (Edwards et al., 2006), phagocytizing cellular debris (Nauta et al., 2003), enhancing axonal elongation (Kigerl et al., 2009), and promoting the proliferation and differentiation of oligodendrocyte progenitor cells (Miron et al., 2013). 
In general wound repair, M1- and M2-like cells are important in the initial inflammatory response and in the subsequent late resolution, respectively. However, in acute-phase SCI, it has been suggested that the lesion is continuously filled with large numbers of M1-like cells that do not transit to M2-like cells (Kigerl et al., 2009), leading to irreversible tissue destruction.

Human adult dental pulp stem cells (DPSCs) and stem cells from human exfoliated deciduous teeth (SHEDs) are selfrenewing mesenchymal stem cells (MSCs) residing within the perivascular niche of the dental pulp (Gronthos et al., 2000; Miura et al., 2003). They are thought to originate from the cranial neural crest, which expresses early markers for both MSCs and neuroectodermal stem cells (Gronthos et al., 2000; Miura et al., 2003; Sakai et al., 2012) and can differentiate into functional neurons and oligodendrocytes under appropriate conditions (Arthur et al., 2008; Király et al., 2009; Sakai et al., 2012). Engrafting these DPSCs promotes functional recovery from various acute and chronic insults of the CNS through paracrine mechanisms that activate endogenous tissue-repairing activities (de Almeida et al., 2011; Leong et al., 2012; Sakai et al., 2012; Taghipour et al., 2012; Inoue et al., 2013; Yamagata et al., 2013; Yamamoto et al., 2014).

Here, we show that the serum-free cultured conditioned medium (CM) from SHEDs (SHED-CM) contains factors that promote marked functional recovery after rat SCI by inducing an M2-dominant neurorepairing microenvironment. We further identified a set of M2 inducers contained in the SHED-CM, monocyte chemoattractant protein-1 (MCP-1) and the secreted ectodomain of sialic acid-binding Ig-like lectin-9 (ED-Siglec-9), that promoted functional recovery after SCI.

\section{Materials and Methods}

Isolation of stem cells from human deciduous teeth. SHEDs were isolated from individuals (aged 6-12 years), and their primary characteristics were analyzed by flow cytometry as described previously (Sakai et al., 2012). SHEDs expressed a set of MSC markers [i.e., cluster of differentiation 90 (CD90), CD73, and CD105], but not endothelial/hematopoietic markers (i.e., CD34, CD45, CD11b/c, or human leukocyte antigen HLA-DR), and exhibited adipogenic, chondrogenic, and osteogenic differentiation. The majority of SHEDs coexpressed Nestin, Doublecortin, $\beta$ III-tubulin, GFAP, S100, A2B5, and CNPase but not adenomatous polyposis coli or MBP. MSCs from human bone marrow lines (BMSCs; from 20- to 22-year-old individuals) at passage 5 and human skinfibroblast lines (Fibro; from 36- to 40-year-old individuals) at passage 5 were obtained from Lonza and the Health Science Research Resources Bank (Sakai et al., 2012), respectively. Ethical approval was obtained from the ethics committee of Nagoya University (permission 8-2). All participants provided written informed consent.

Preparation of CM. At passage 3-9, SHEDs, BMSCs, or Fibros at 70$80 \%$ confluency were washed with PBS, and the culture medium was replaced with serum-free DMEM. After a $48 \mathrm{~h}$ incubation, the medium was collected and centrifuged for $4-5 \mathrm{~min}$ at $440 \times \mathrm{g}$. The supernatant was collected and centrifuged for $1 \mathrm{~min}$ at $4^{\circ} \mathrm{C}$ at $17,400 \times g$. The supernatant was used for assays or measured for protein concentration using the BCA protein assay kit (Pierce). CM protein concentrations were adjusted to $3 \mu \mathrm{g} / \mathrm{ml}$ with DMEM. The survival rates of the three cell lines were examined with the trypan blue exclusion test after $48 \mathrm{~h}$ of serumfree culture (data not shown).

Isolation of mouse and rat bone marrow macrophages and cell culture. Bone marrow cells were isolated from the femurs of adult Sprague Dawley rats, C57BL/6 mice, or B6.129 (Cg)-Ccr2 ${ }^{\text {tm2.1Ifc } / J ~ m i c e ~(T h e ~ J a c k s o n ~}$ Laboratory). They were differentiated into the macrophage lineages in DMEM supplemented with $20 \mathrm{ng} / \mathrm{ml}$ macrophage colony-stimulating factor (Peprotech) at $37^{\circ} \mathrm{C}$ in $5 \% \mathrm{CO}_{2}$ for $7-8 \mathrm{~d}$.

Isolation of rat cerebellar granule neurons. Sprague Dawley rats at postnatal day 7 were killed, and the cerebella were collected. The tissues were minced and digested using a Papain Dissociation System (Worthington). Dissociated cells were applied to a 35/60\% two-step Percoll gradient and centrifuged at $3000 \times g$ for $15 \mathrm{~min}$. Cerebellar granule neurons (CGNs) at the interface were collected. Cells were suspended in Neurobasal medium (Invitrogen) supplemented with 2\% B27 (Invitrogen), 2 mM glutamine, and an additional $20 \mathrm{~mm} \mathrm{KCl}$.

Rat contusion model and surgical procedure. Eight-week-old adult female Sprague Dawley rats weighing 200-230 g were used. The animals were anesthetized with an intraperitoneal injection of ketamine (60-90 $\mathrm{mg} / \mathrm{kg}$ ) and xylazine ( $100-150 \mathrm{mg} / \mathrm{kg}$ ). After Th9 laminectomy, the dura mater was exposed and a $200 \mathrm{kdyn}$ injury force was induced with a commercially available SCI device (Infinite Horizon Impactor; Precision Systems and Instrumentation). Using this protocol, we obtained a consistent degree of spinal cord contusion injury. The Basso, Beattie, and Bresnahan (BBB) score at 8 weeks after injury was $4-6$ in a previously published paper independent of ours (Imagama et al., 2011; Wakao et al., 2011; Tauchi et al., 2012), as well as in this study. Immediately after the spinal cord contusion, a Th12 partial laminectomy was performed, and a thin micro silicone tube $(0.3 \mathrm{~mm}$ inner diameter, $0.5 \mathrm{~mm}$ outer diameter) was inserted intrathecally under a surgical microscope. The tube was connected to an iPRECIO SMP-200 pump (Primetech) filled with CMs or $1 \mu \mathrm{g} / \mathrm{ml} \mathrm{MCP-1/Siglec-9.} \mathrm{The} \mathrm{tube} \mathrm{was} \mathrm{sutured} \mathrm{to} \mathrm{the} \mathrm{spinous} \mathrm{process}$ to anchor it in place, and the pump was placed under the skin on the animal's axilla. For SHED transplantation, $1 \times 10^{6}$ cells were drawn into a glass pipette (tip diameter, $50-70 \mu \mathrm{m}$ ), which was mounted on a $10 \mu \mathrm{l}$ Hamilton syringe attached to a micromanipulator. First, the cells were deposited into two injection sites at the rostral and caudal stumps, $2 \mathrm{~mm}$ from the lesion and $0.5 \mathrm{~mm}$ lateral to the midline, at a depth of $1.5 \mathrm{~mm}$. A $2.5 \mu \mathrm{l}$ sample containing $2.5 \times 10^{5}$ cells in PBS was injected into each site (injection rate, $0.8 \mu \mathrm{l} / \mathrm{min}$ ). Next, $1 \times 10^{5}$ cells in fibrin glue were implanted into the lesion epicenter. All of the treated rats were given cyclosporine (Novartis) at $10 \mathrm{mg} \cdot \mathrm{kg}^{-1} \cdot \mathrm{d}^{-1}$ on the day before transplantation and then every day afterward. As postoperative care, the bladder was compressed by manual abdominal pressure twice a day until bladder function was restored. The rats were examined for damage induced by the intrathecal insertion of the catheter. Those undergoing catheter insertion without contusion $(\mathrm{Ca}+/ \mathrm{Co}-; n=5)$ exhibited little or no deficit in locomotor function, whereas rats subjected to contusion without catheter insertion $(\mathrm{Ca}-/ \mathrm{Co}+; n=7)$ rats exhibited functional deficits similar to the control groups shown in Figures $1 A, 6 B, 7 A$, and $8 D$. The $\mathrm{Ca}+/ \mathrm{Co}-$ spinal cord exhibited no obvious atrophy or histological damage, whereas that from $\mathrm{Ca}-/ \mathrm{Co}+$ exhibited severe atrophy caudal to the injury site (data not shown). Together, these findings demonstrated that the SCI was generated by contusion damage and not by the catheter insertion. For the analysis of hindlimb locomotor function, only animals showing complete paralysis (BBB score of 0 ) the day after the operation were used. Animals that could move their hindpaw were excluded, as were animals that died immediately after the surgery. In this study, the rate of hindpaw movement the day after the operation was $9.44 \%$, and the rate of death was $22.78 \%$ in all the operated rats over the entire recovery period ( 8 weeks of observation). Animal studies were conducted in accordance with the National Institutes of Health Guide for the Care and Use of Laboratory Animals and were approved by the Animal Research Committee of Nagoya University. Extracted teeth were collected at the Nagoya University School of Medicine, under approved guidelines set by Nagoya University (H-73, 2003).

BBB open-field locomotor score. The 22-point (from 0 to 21) BBB locomotor rating scale (Basso et al., 1995) was used to assess hindlimb locomotor recovery, including joint movements, stepping ability, coordination, and trunk stability. A score of 21 indicates unimpaired locomotion as observed in uninjured rats. Two examiners who were blinded to the animals' treatment performed the tests. The duration of each session was $4 \mathrm{~min} / \mathrm{rat}$. The scores were analyzed by repeated-measures ANOVA with Tukey's multiple comparison tests at each time point.

M2-like bone marrow macrophage induction assay. Differentiated rat bone marrow macrophages (BMMs) were plated on $6 \mathrm{~cm}$ dishes $(2.0 \times$ $10^{6}$ cells per dish) for real-time quantitative PCR (qPCR) or 48 -well tissue culture plates $\left(2.0 \times 10^{5}\right.$ cells per well in triplicate $)$ for immunohistochemical analysis with serum-free DMEM, SHED-CM, BMSC-CM, 
$100 \mathrm{ng} / \mathrm{ml}$ recombinant human MCP-1/CC chemokine ligand 2 (CCL2; 300-04; Peprotech), 100 ng/ml MCP-1/recombinant human Siglec-9 (1139-SL; R\&D Systems), or $20 \mathrm{ng} / \mathrm{ml} \mathrm{IL-4} \mathrm{(R \& D} \mathrm{Systems).} \mathrm{After} \mathrm{a} 24 \mathrm{~h}$ incubation, the mRNA expressions of markers and the CD206 (rabbit IgG, 1:1000; ab64693; Abcam) or CD68 (mouse IgG, 1:300; MAB1435; Millipore) protein expression were examined. CD206/DAPI-positive cells were counted in five random sites per well and divided by the number of DAPI-positive total cells in the site. For neutralization, $2.5 \mu \mathrm{g} / \mathrm{ml}$ anti-human CCL2/MCP-1 antibody (mouse IgG; MAB279; R\&D Systems), anti-human Siglec-9 antibody (mouse IgG; ab89484; Abcam), or anti-human IL-6 antibody (mouse IgG; MAB206; R\&D Systems) was used. The SHED-CM was incubated for $30 \mathrm{~min}$ with the Abs at $37^{\circ} \mathrm{C}$ before the assay. For sialidase treatment, rat BMMs were incubated for $2 \mathrm{~h}$ at $37^{\circ} \mathrm{C}$ in $5 \% \mathrm{CO}_{2}$ with serum-free DMEM supplemented with 10 $\mathrm{mU} / \mathrm{ml}$ Neuraminidase (Roche) before applying the SHED-CM. For CC chemokine receptor 2 (CCR2) inhibition, rat BMMs were incubated for $30 \mathrm{~min}$ at $37^{\circ} \mathrm{C}$ in $5 \% \mathrm{CO}_{2}$ with serum-free DMEM containing $50 \mu \mathrm{M}$ RS504393 (6-methyl-1' - [2-(5-methyl-2-phenyl-4-oxazolyl)ethyl]-spiro [4H-3,1-benzoxazine-4,4'-piperidin]-2( $1 H)$-one; Tocris Bioscience) before applying MCP-1 or ED-Siglec-9 or MCP-1/ED-Siglec-9.

Neurite outgrowth and apoptosis assays. Forty-eight-well tissue culture plates were coated with $10 \mu \mathrm{g} / \mathrm{ml}$ poly-L-lysine (PLL) and then with or without $300 \mathrm{ng} / \mathrm{ml}$ chondroitin sulfate proteoglycan (CSPG; Millipore). The CGNs were seeded at $1.8 \times 10^{5}$ cells per well. They were then cultured at $37^{\circ} \mathrm{C}$ in $5 \% \mathrm{CO}_{2}$ with serum-free DMEM, $100 \mathrm{ng} / \mathrm{ml}$ recombinant human MCP-1/ED-Siglec-9, or rat macrophage-CMs, which were generated by the overnight culture of BMMs in MCP-1/ED-Siglec- 9 or IL-4. After a $24 \mathrm{~h}$ incubation, the CGNs were fixed in $4 \%$ paraformaldehyde/PBS and stained with TUNEL (In Situ Cell Death Detection kit; Roche) and anti-neuron-specific $\beta$-tubulin (mouse IgG, 1:200; MAB1195; R\&D Systems). The cell processes were defined as neurites when they were longer than the diameter of the cell body. Neurite length was evaluated by manual tracing using the software NIH ImageJ (version 1.29) and referenced to a known length. For each experiment, at least 100 CGNs were randomly counted and measured. To calculate the percentage of cell apoptosis, TUNEL/DAPI-positive cells were counted in five random sites per well and divided by the number of DAPI-positive total cells in the site. Each experiment was conducted in triplicate, and images were taken containing $\geq 300$ cells per site.

Measurement of cytokines in CMs and protein depletion assays. MCP-1, Siglec-9, and IL-6 in CMs were determined by the ELISA kit (Quantikine ELISA Human CCL2/MCP-1 and Human IL-6 from R\&D Systems; RayBio Human Siglec-9 ELISA Kit from Raybiotech). To deplete the SHED-CM of MCP-1 and Siglec-9, anti-MCP-1 and anti-Siglec-9 antibodies preattached to Protein G Sepharose (GE Healthcare) were added to the SHED-CM, the mixture was incubated overnight at $4^{\circ} \mathrm{C}$, and the antibody beads were removed by centrifugation. The loss of MCP-1 and Siglec-9 from the SHED-CM was confirmed by ELISA.

Cytokine antibody array. The cytokine antibody array experiments were performed using the RayBio Human Cytokine Antibody Array G Series 4000 (applied arrays; Raybiotech) at Filgen. Using laser scanning, cytokines in SHED-CM, BMSC-CM, and serum-free DMEM were detected by 274 -human-cytokine array plates. All scans were performed in duplicate, and data were calculated as the ratio of the level in SHED-CM to that in BMSC-CM or serum-free DMEM.

Real-time qPCR. Total RNA was quantified by a spectrophotometer, and RNA integrity was checked on $1 \%$ agarose gels. RT reactions were performed with Superscript III reverse transcriptase (Invitrogen) using $0.5 \mu \mathrm{g}$ of total RNA in a $25 \mu \mathrm{l}$ total reaction volume. Real-time $\mathrm{qPCR}$ was performed using the THUNDERBIRD SYBR qPCR Mix (Toyobo) driven by the StepOnePlus Real-Time PCR System (Applied Biosystems). Primers were designed using primer 3 (Table 1 ).

Histology and immunohistochemical analysis. For histological examination of the treated spinal cords, the animals were anesthetized and transcardially perfused with $4 \%$ paraformaldehyde in $0.1 \mathrm{~m}$ PBS. The spinal cords were embedded in OCT compound (Sakura Finetek) and sectioned in the sagittal or axial plane at $20 \mu \mathrm{m}$ on a cryostat (Leica). The spinal cord region with the greatest damage is referred to as the "lesion epicenter." We isolated the spinal cord $\pm 10 \mathrm{~mm}$ from the epicenter and
Table 1. Rat and mouse primers for real-time qPCR

\begin{tabular}{|c|c|c|c|}
\hline Origin & Primer & Sequence (forward $5^{\prime}-3^{\prime}$ ) & Sequence (reverse $5^{\prime}-3^{\prime}$ ) \\
\hline Rat & Gapdh & AACTTTGGCATCGTGGAAGG & CGGATACATTGGGGGTAGGA \\
\hline Rat & $11-6$ & TTGCCTTCTTGGGACTGATG & ACTGGTCTGTTGTGGGTGGT \\
\hline Rat & $\|-1 \beta$ & CAGGATGAGGACCCAAGCAC & TCAGACAGCACGAGGCATTT \\
\hline Rat & $\operatorname{Inf}-\alpha$ & CTCGAGTGACAAGCCCGTAG & CCTTGAAGAGAACCTGGGAGTAC \\
\hline Rat & iNos & GGCAGGATGAGAAGCTGAGG & CCGCATTAGCACAGAAGCAA \\
\hline Rat & $\|-10$ & GCCTGCTCTTACTGGCTGGA & TCTGGCTGACTGGGAAGTGG \\
\hline Rat & Tgf- $\beta 1$ & CCGCAACAACGCAATCTATG & GCACTGCTTCCCGAATGTCT \\
\hline Rat & Vegf & ACCAAAGCCAGCACATAGGA & GGGGCATTAACTGCATCTGG \\
\hline Rat & $C d 206$ & GCAGGTGGTTTATGGGATGTTT & TTTGGGTTCAGGAGTTGTTGTG \\
\hline Rat & Arginase1 & CACCTGAGTTTTGATGTTGATGG & TCCTGAAAGTAGCCCTGTCTTGT \\
\hline Rat & $Y_{m 1}$ & TGCCAACATCAGCAACAACA & ССATCCTCCAACAGACAGCA \\
\hline Rat & $\mathrm{C}(\mathrm{r} 2$ & AGAGGCATAGGGCTGTGAGG & CCTGGAAGGTGGTCAGGAAG \\
\hline Rat & Bdnf & CGTCCCTGGCTGACACTTTT & TCCGCGTCCTTATGGTTTTC \\
\hline Rat & Hgf & GCAAGACATGTCAGCGCTGG & CCAAGGGGTGTCAGGGTCAA \\
\hline Mouse & Gapdh & AACTTTGGCATTGTGGAAGG & GGATGCAGGGATGATGTTCT \\
\hline Mouse & $C d 206$ & TCTCCCGGAACCGACTCTTC & AACTGGTCCCCTAGTGTACGA \\
\hline Mouse & $\|-10$ & GCTCTTACTGACTGGCATGAG & CGCAGCTCTAGGAGCATGTG \\
\hline
\end{tabular}

Hgf, hepatocyte growth factor.

prepared serial axial sections. Based on the total length of the sectioned specimen, we estimated the position of the epicenter. For immunohistochemical analysis, spinal cord sections were permeabilized with $0.1 \%$ $(\mathrm{v} / \mathrm{v})$ Triton X-100 in PBS for $20 \mathrm{~min}$, blocked with $5 \%(\mathrm{v} / \mathrm{v})$ bovine serum albumin for $30 \mathrm{~min}$, and incubated overnight with the following primary Abs: 5-hydroxytryptamine (5-HT; rabbit IgG, 1:500; S5545; Sigma-Aldrich), ionized calcium-binding adapter molecule 1 (Iba1; goat IgG, 1:500; ab5076; Abcam), CD206 (rabbit IgG, 1:1000; ab64693; Abcam), and IL-10 (mouse IgG, 1:250; ab25073; Abcam). The following secondary Abs were used: anti-mouse IgG-Alexa Fluor 488, anti-rat IgGAlexa Fluor 488, anti-rabbit IgG-Alexa Fluor 546, anti-goat IgG-Alexa Fluor 546, and anti-rabbit IgG-Alexa Fluor 647. After counterstaining with DAPI (Sigma-Aldrich), tissue images were obtained with a universal fluorescence microscope (BZ9000; Keyence). CD206/Iba1-positive cells were counted in five random sites per section surrounding the injured region ( $\pm 1 \mathrm{~mm}$ from the epicenter, five sagittal sections per animal) and divided by the number of Iba1-positive cells at the site. 5-HT-positive nerve fibers were counted in each region of five sagittal sections per animal and divided by the 5-HT-positive nerve fiber number in the sham-operated animal. To evaluate the tissue damage, axial planes $3 \mathrm{~mm}$ caudal to the injury epicenter were stained with Sudan black B (Wako), and the residual gray- and white-matter areas were measured by a BZAnalyzer (Keyence). All tissue staining evaluations were performed for at least three animals per group.

Western blot, lectin blot, and coimmunoprecipitation. To detect EDSiglec-9 in CMs, the CMs were concentrated 50 times by acetone precipitation. The CM pellets were then resuspended with lysis buffer $(1 \%$ Triton X-100, $150 \mathrm{~mm} \mathrm{NaCl}, 20 \mathrm{~mm}$ Tris- $\mathrm{HCl}$, and $2 \mathrm{~mm} \mathrm{CaCl}_{2}$ ), separated by SDS-PAGE, and electroblotted onto an Immobilon-P PVDF membrane. An antibody against human Siglec-9 (goat IgG, 1:1000; AF1139; R\&D Systems) was used to probe the membranes.

To detect the CD206 protein in vivo, rat spinal cords $( \pm 2 \mathrm{~mm}$ from the injury epicenter) were collected $72 \mathrm{~h}$ after SCI and probed with an antibody against rat CD206 (rabbit IgG, 1:1000; ab64693; Abcam). The protein bands were detected with ECL prime (GE Healthcare) and analyzed by an LAS-4000 mini lumino-image analyzer (GE Healthcare). To evaluate the CD206 protein expression intensity, each CD206 band was measured by Image Quant TL (GE Healthcare) and divided by the $\beta$-actin intensity.

The lectin blot analysis was performed as described previously (Geisler and Jarvis, 2011). Briefly, CCR2 protein, immunoprecipitated from THP-1, a human monocytic cell line derived from an acute monocytic leukemia patient (RIKEN Cell Bank), lysate with an anti-CCR2 Ab (rabbit IgG, 1:50; ab32144; Abcam), was separated by SDS-PAGE. After blotting, the membranes were blocked with MAL buffer (10 mM HEPES, pH 7.5, $150 \mathrm{~mm} \mathrm{NaCl}, 0.2 \% \mathrm{BSA}$, and $0.2 \%$ Tween 20 ) for $12 \mathrm{~h}$ at $4^{\circ} \mathrm{C}$ and subsequently probed with $5 \mathrm{mg} / \mathrm{ml}$ biotinylated MAL (Vector Laborato- 

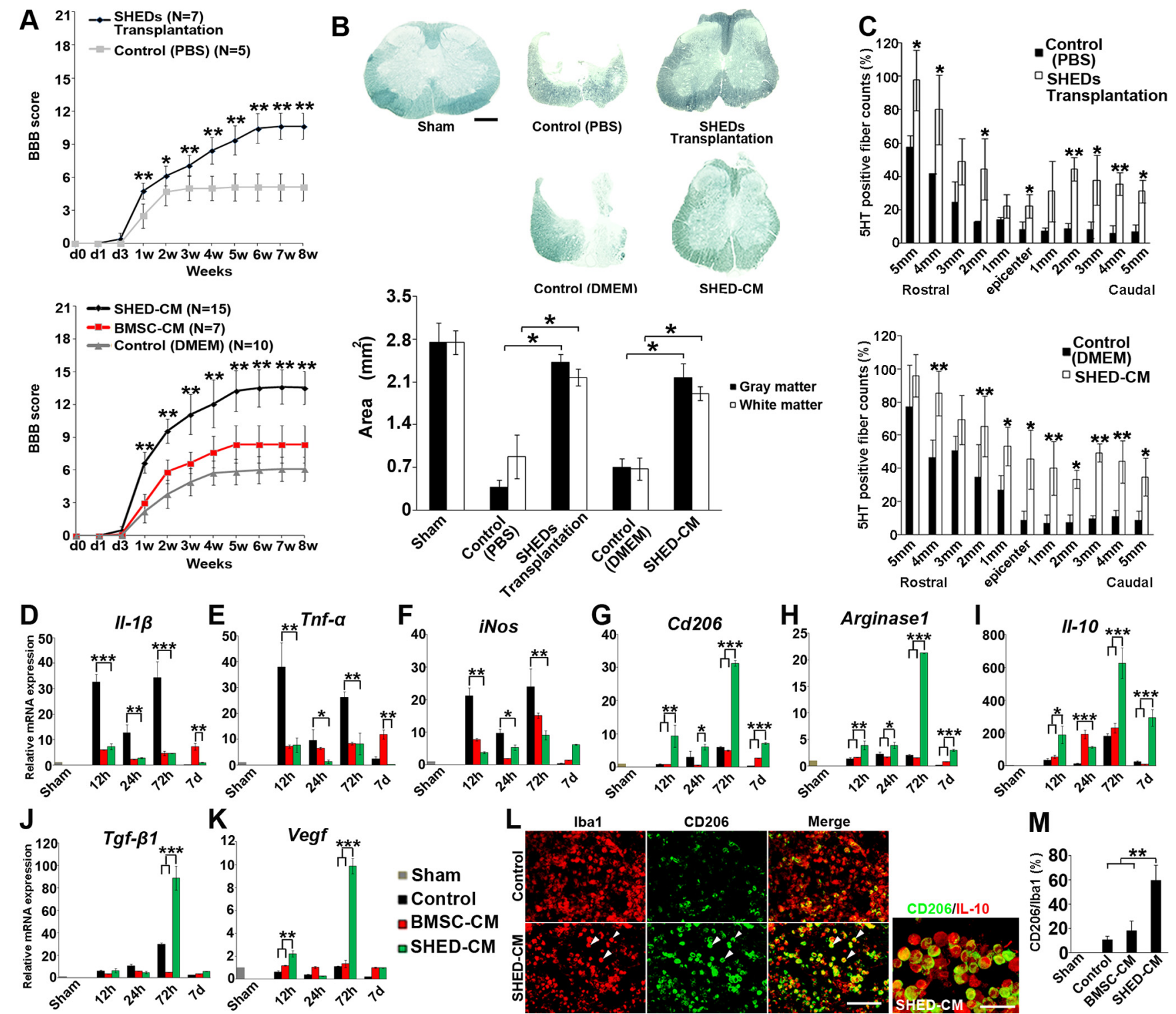

Figure 1. Therapeutic benefits of SHEDs or SHED-CM for SCI. $A$, Hindlimb functional recovery after spinal cord contusion. Top, SHED transplantation, $n=7$; PBS, $n=5$. Bottom, SHED-CM, $n=$ 15; BMSC-CM, $n=7$; serum-free DMEM, $n=10$. ANOVA with Tukey's post hoc test. B, Sudan black B staining of axial spinal cord sections $3 \mathrm{~mm}$ caudal to the epicenter 8 weeks after SCl and quantification of gray and white matter areas $3 \mathrm{~mm}$ caudal to the epicenter. ANOVA with Tukey's post hoc test ( $n=3$ rats per group). C, Quantification of the 5 -HT-positive nerve fibers in sagittal sections of the spinal cord, 8 weeks after $\mathrm{SCl}$. $x$-Axis indicates specific locations along the spinal cord rostrocaudal axis. Results are expressed relative to the value in sham-operated rats at the Th9 level. ANOVA with Tukey's post hoc test ( $n=3$ rats per group). $\boldsymbol{D}-\boldsymbol{K}, \mathrm{qPCR}$ analysis of the indicated mRNAs in CM-treated spinal cords over time. Results are expressed relative to the level in the sham-operated model. ANOVA with Tukey's post hoc test ( $\pm 2 \mathrm{~mm}$ from epicenter, $n=3$ rats per group). $L$, Representative images of immunohistological staining of microglia/macrophages surrounding the lesion ( $\pm 1 \mathrm{~mm}$ from epicenter) $72 \mathrm{~h}$ after SCI. Antibodies used and treatment groups are indicated at top and left, respectively. CD206 ${ }^{+}$cells in SHED-CM-treated spinal cord highly coexpressed IL-10. Arrowheads indicate CD206 ${ }^{+} / \mathrm{lba} 1^{+}$cells. $M$, Quantification of CD206 ${ }^{+} / \mathrm{lba} 1^{+}$cells in treated spinal cords. AN0VA with Tukey's post hoc test $(n=3$ rats per group and 5 sections per animal). Scale bars: $\boldsymbol{B}, 500 \mu \mathrm{m} ; \boldsymbol{L}, 100 \mu \mathrm{m}$. Mean \pm SD $(\boldsymbol{A}-\boldsymbol{C}$ and $\boldsymbol{M})$ and mean $\pm \operatorname{SEM}(\boldsymbol{D}-\boldsymbol{K}) .{ }^{*} p<0.05,{ }^{* *} p<0.01,{ }^{* * *} p<0.001$.

ries) in MAL buffer for $12 \mathrm{~h}$ at $4^{\circ} \mathrm{C}$. The MAL was detected with avidinHRP (Vector Laboratories) and ECL.

To analyze the physical interaction between ED-Siglec-9 and CCR2, THP-1 lysate was incubated overnight at $4^{\circ} \mathrm{C}$ with $0.15 \mathrm{~nm}$ ED-Siglec9-Fc or Fc and was then immunoprecipitated with Protein A Sepharose (GE Healthcare). The total cell lysate and resuspended precipitate were immunoblotted with an antibody against murine CCR2 (rabbit IgG, 1:500; ab32144; Abcam).

In vivo CCR2 inhibition assay. To investigate the relationship between CCR2 and MCP-1/ED-Siglec-9 signaling, 2 mg/kg RS504393 was given to rats orally every $12 \mathrm{~h}$ for 1 week, starting $36 \mathrm{~h}$ after SCI. Three days after SCI, the expressions of Iba1 and CD206 were evaluated immunohistologically. Eight weeks after SCI, the tissue damage and 5-HT-positive fibers were evaluated.
Statistics. An unpaired two-tailed Student's $t$ test was used for single comparisons. To analyze more than three independent groups, we used repeated-measures ANOVA with Tukey's post hoc test (SPSS version 19.0). A $p$ value $<0.05$ was considered significant.

\section{Results}

Treatment with SHEDs or SHED-CM promotes functional recovery after SCI

We first examined the effects of SHEDs or their CM on functional recovery in a rat contused SCI model. Throughout the observation period, animals receiving transplanted SHEDs or intrathecally administered SHED-CM showed significantly better recovery than those treated with $\mathrm{PBS}$, BMSC-CM, or cell-culture 


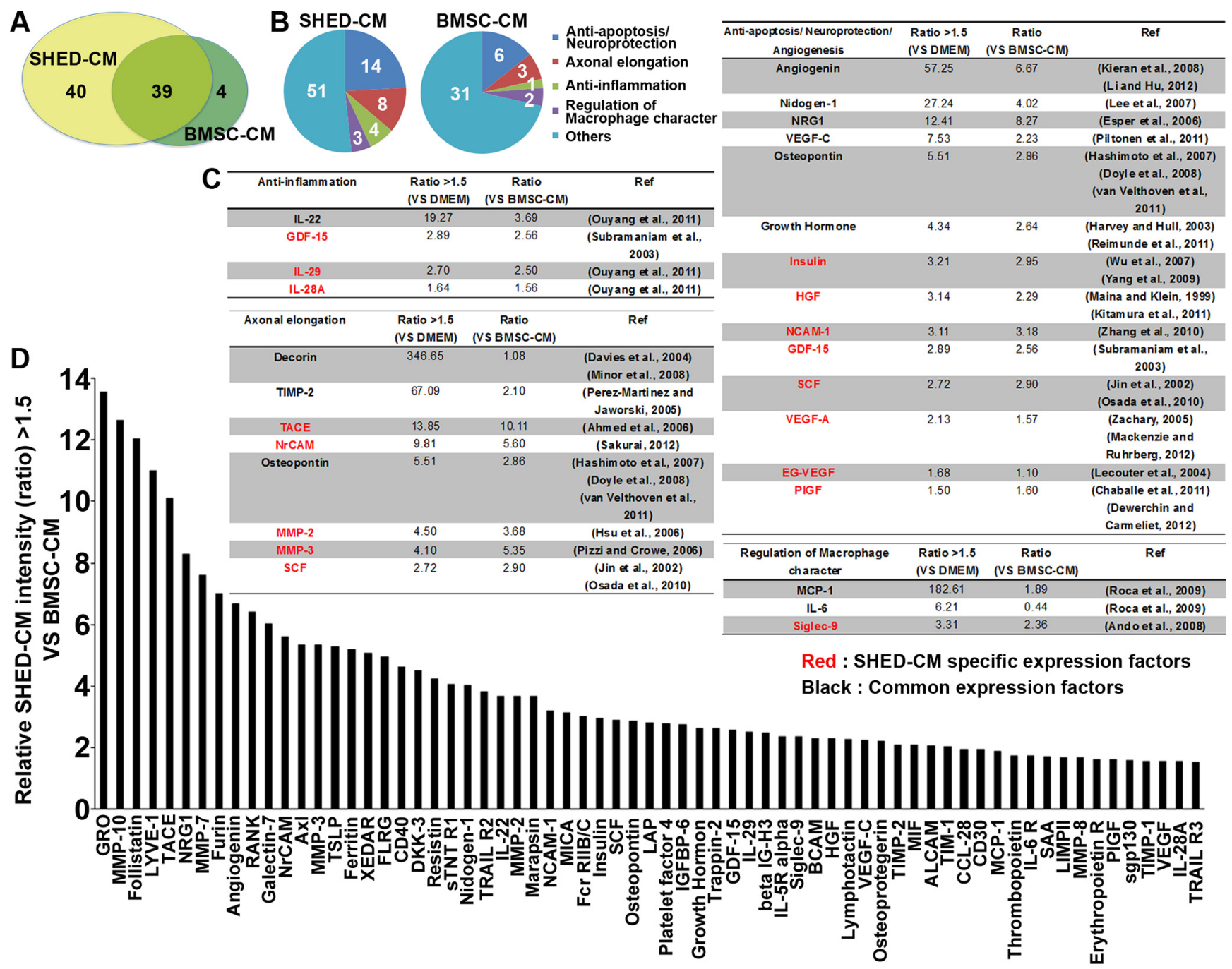

Figure 2. SHED-CM contains more neuroregenerative factors than BMSC-CM. A, Summary of the cytokine antibody array analysis of SHED-CM and BMSC-CM. B, Cluster analysis of the SHED-CM and BMSC-CM based on reported function. C, Cluster analysis of the SHED-CM soluble factors. SHED-CM contained 28 proteins known to be involved in neuroregenerative processes, including anti-apoptosis/neuroprotection, axonal elongation, anti-inflammation, and the regulation of macrophage properties. Red, Factors detected only in SHED-CM. Black, Factors present in both SHED-CM and BMSC-CM. D, Factors expressed in SHED-CM at levels $>1.5$ times those in BMSC-CM. The $y$-axis indicates the relative intensity in SHED-CM compared with BMSC-CM.

medium (DMEM; Fig. 1A). Eight weeks after SCI, the rats treated with SHEDs or SHED-CM could support their weight through the plantar paw surface and could coordinate forelimb and hindlimb steps appropriately $(p<0.01)$. In contrast, rats treated with BMSC-CM or vehicle could not support their weight $(p<$ 0.01 ). Rats treated with SHEDs or SHED-CM exhibited less tissue loss and more 5-HT-positive descending raphe spinal axon fibers over the epicenter in the spinal cord compared with the control rats (Fig. $1 B, C$ ). Together, these results demonstrated that SHED transplantation and SHED-CM administration exhibit similar neurorepairing activities in the treatment of SCI.

Effect of CMs on the SCI inflammatory response

During the acute phase of SCI, the expressions of proinflammatory cytokines (Il-1 $\beta$ and Tnf- $\alpha$ ) and of inducible nitric oxide synthases (iNos) were transiently upregulated at 12 and $72 \mathrm{~h}$. Treatment with SHED-CM or BMSC-CM similarly suppressed these proinflammatory mediators for 1 week after the injury (Fig. $1 D-F)$. Notably, SHED-CM but not BMSC-CM upregulated the expression of the M2 genes Il-10, Tgf- $\beta 1$, Vegf, Cd206, and Arginase1 (Fig. $1 G-K$ ). Immunohistochemical analysis showed an accumulation of IL-10-expressing CD206 ${ }^{+}$M2-like cells around the epicenter in SHED-CM-treated spinal cords (Fig. 1L). Quantitative analysis revealed that, of the microglia/macrophages in the SHED-CM and BMSC-treated spinal cords, $59.44 \pm 12.7$ and $18.12 \pm 8.1 \%$ were CD206 ${ }^{+}$M2-like cells, respectively (Fig. $1 M$ ). These data indicated that SHED-CM has an M2-inducing activity.

Factors in SHED-CM that induce macrophage differentiation To identify factors responsible for the therapeutic effects of $\mathrm{CMs}$, we characterized the soluble factors in SHED-CM and BMSC-CM by cytokine antibody array analysis. SHED-CM and BMSC-CM contained 79 and 43 proteins, respectively, at levels 1.5 -fold or higher than those found in the control DMEM background, which is the threshold for a significant difference according to the manual of the company (Raybiotech). Of these, 40 proteins were preferentially expressed in SHED-CM, whereas 39 were present in both SHED-CM and BMSC-CM (Fig. 2A). Of the 79 proteins expressed in SHED-CM, 28 were known to be involved in neuroregenerative processes, such as anti-apoptosis/ neuroprotection, axonal elongation, anti-inflammation, and the regulation of macrophage properties (Fig. $2 B-D$ ). 

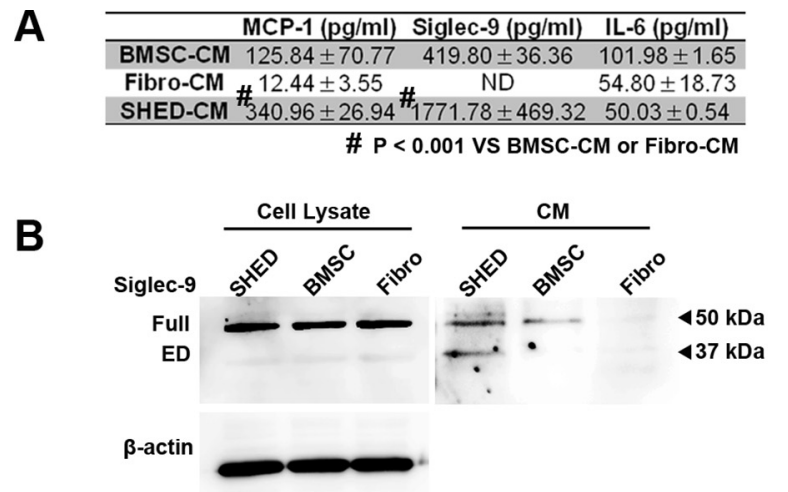

D
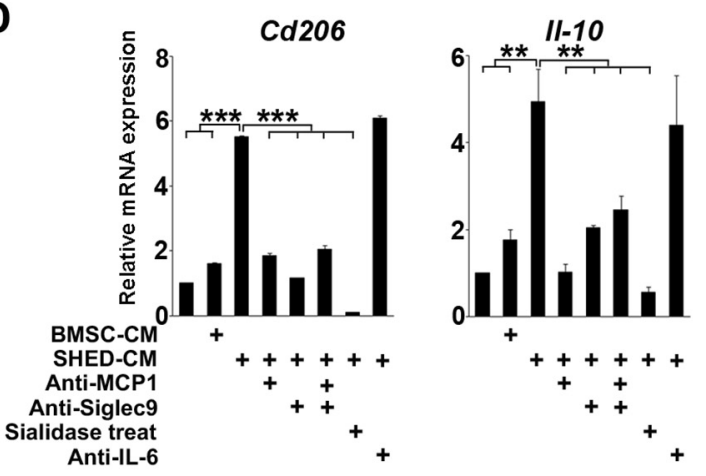

C

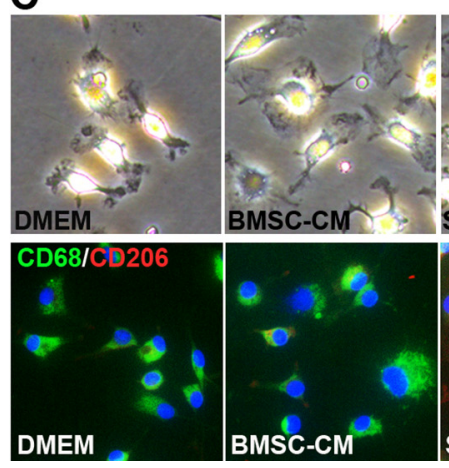

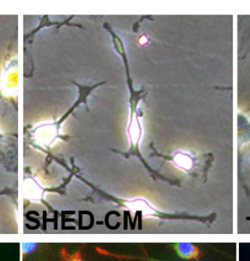
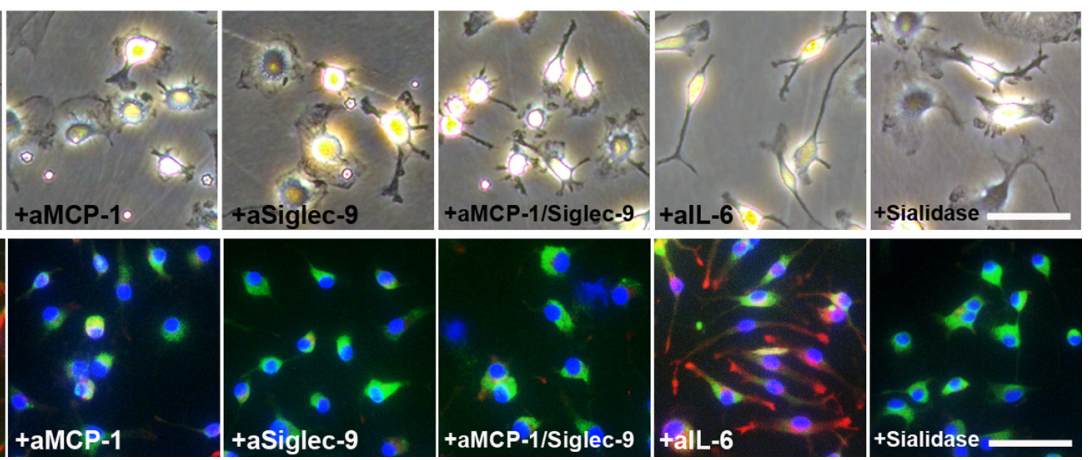

Figure 3. MCP-1 and Siglec-9 are essential for SHED-CM-mediated M2-like macrophages induction. $\boldsymbol{A}$, Quantification of MCP-1, Siglec-9, and IL-6 in CMs. $\boldsymbol{B}$, Immunoblot analysis with an ED-Siglec-9-specific antibody. Full, Full-length Siglec-9; ED, ectodomain of Siglec-9. C, D, In vitro M2 induction assay with rat primary BBMs. C, Representative images of BMMs treated with DMEM, BMSC-CM, SHED-CM, or SHED-CM with three different antibodies or sialidase. Top, 0ptical-microscopy images; bottom, CD206/CD68/DAPI immunostaining. D, qPCR analysis of Cd206 and IL-10 mRNA expression. Results are relative to DMEM treatment. Sialidase treatment suppressed the SHED-CM-mediated M2 induction. ANOVA with Tukey's post hoc test ( $n=3$ separate experiments). Scale bar: $\boldsymbol{C}, 50 \mu \mathrm{m}$. Mean \pm SD $(\boldsymbol{A})$ and mean \pm SEM $(\boldsymbol{D}) .{ }^{* *} p<0.01 ;{ }^{* * *} p<0.001$.

Based on the differential expression profiles of the soluble factors and the previously described functional properties of each protein, we ascertained that MCP-1, Siglec-9, and IL-6 might be involved in the M2-like macrophage differentiation. MCP-1 is a classically identified member of a chemokine superfamily that recruits immune cells into tissue lesions (Shachar and Karin, 2013). The Siglecs are a large family of sialic acid-binding I-type transmembrane Ig-like lectins that modulate the immune signaling on various types of immune cells (Crocker et al., 2007; Linnartz and Neumann, 2013). The role of the secreted ED-Siglec-9 in inflammation and other cellular responses is unknown.

ELISAs revealed that the levels of MCP-1 and Siglec-9 were higher in SHED-CM than in BMSC-CM (Fig. 3A). Immunoblot analysis with antibodies specific for ED-Siglec-9 detected two proteins with different molecular weights in SHED, BMSC, and fibroblast cell lysates (Fig. 3B); the larger and smaller bands appeared to represent the full-length transmembrane and secreted ED forms of Siglec-9, respectively. The full-length Siglec-9 was found in both BMSC-CM and SHED-CM and might be secreted into the $\mathrm{CM}$ through exosome-mediated exocytosis. However, although the secreted ED-Siglec-9 was present in SHED-CM, little or none was present in BMSC-CM or the CM from fibroblasts. According to the GenBank data, full-length human Siglec-9 and predicted ED-Siglec-9, respectively, consist of 464 and 331 aa and have a molecular weight of 50 and $35 \mathrm{kDa}$ on SDS-PAGE. Our immunoblot analysis uniquely detected the $35 \mathrm{kDa}$ band in the SHED-CM (Fig. 3B). These findings suggest strongly that the ED-Siglec-9 in SHED-CM was the full ED of human Siglec-9, which may be generated by ED shedding by a specific protease on the cell surface of SHEDs.
The M1- and M2-like macrophages derived from BMMs display distinct cell shapes: M2-like cells are elongated compared with M1-like cells (McWhorter et al., 2013). We found that rat BMMs maintained a spherical cell shape under the DMEM control conditions or in BMSC-CM, whereas BMMs in SHED-CM were elongated and expressed a high level of CD206 (Fig. 3C). SHED-CM significantly increased the expression of the M2 markers $\mathrm{Cd} 206$ and $\mathrm{Il}-10$ (Fig. 3D). Notably, neutralizing antibodies against MCP-1 and Siglec-9, but not against IL-6, inhibited the SHED-CM-mediated induction of the M2 markers (Fig. $3 C, D)$. Pretreating BMMs with sialidase abolished the SHEDCM-mediated M2 induction, supporting the role of Siglec-9 in this activity (Fig. 3C,D). These results indicated that both MCP-1 and ED-Siglec-9 are essential for the SHED-CM-mediated induction of M2-like macrophages in vitro.

\section{MCP-1 and ED-Siglec-9 synergistically induce M2 through CCR2}

We next examined whether MCP-1 and ED-Siglec-9 were sufficient to induce the M2 differentiation of BMMs in vitro. Although neither MCP-1 nor ED-Siglec-9 alone could induce BMMs to express the M2 genes, combined, they induced M2 gene expression and an elongated morphology in the BMMs (Fig. $4 A, B)$. MCP-1/ED-Siglec-9 also increased the expression of $C$ cr 2 (Fig. 4C). These data indicated that MCP-1 and ED-Siglec-9 synergistically promote $\mathrm{M} 2$ differentiation.

Next, we examined whether CCR2, the MCP-1 receptor, is required for the MCP-1/ED-Siglec-9-mediated M2 induction of BMMs. Treatment with a selective CCR2 antagonist, RS504393, inhibited the MCP-1/ED-Siglec-9-induced expression of M2 

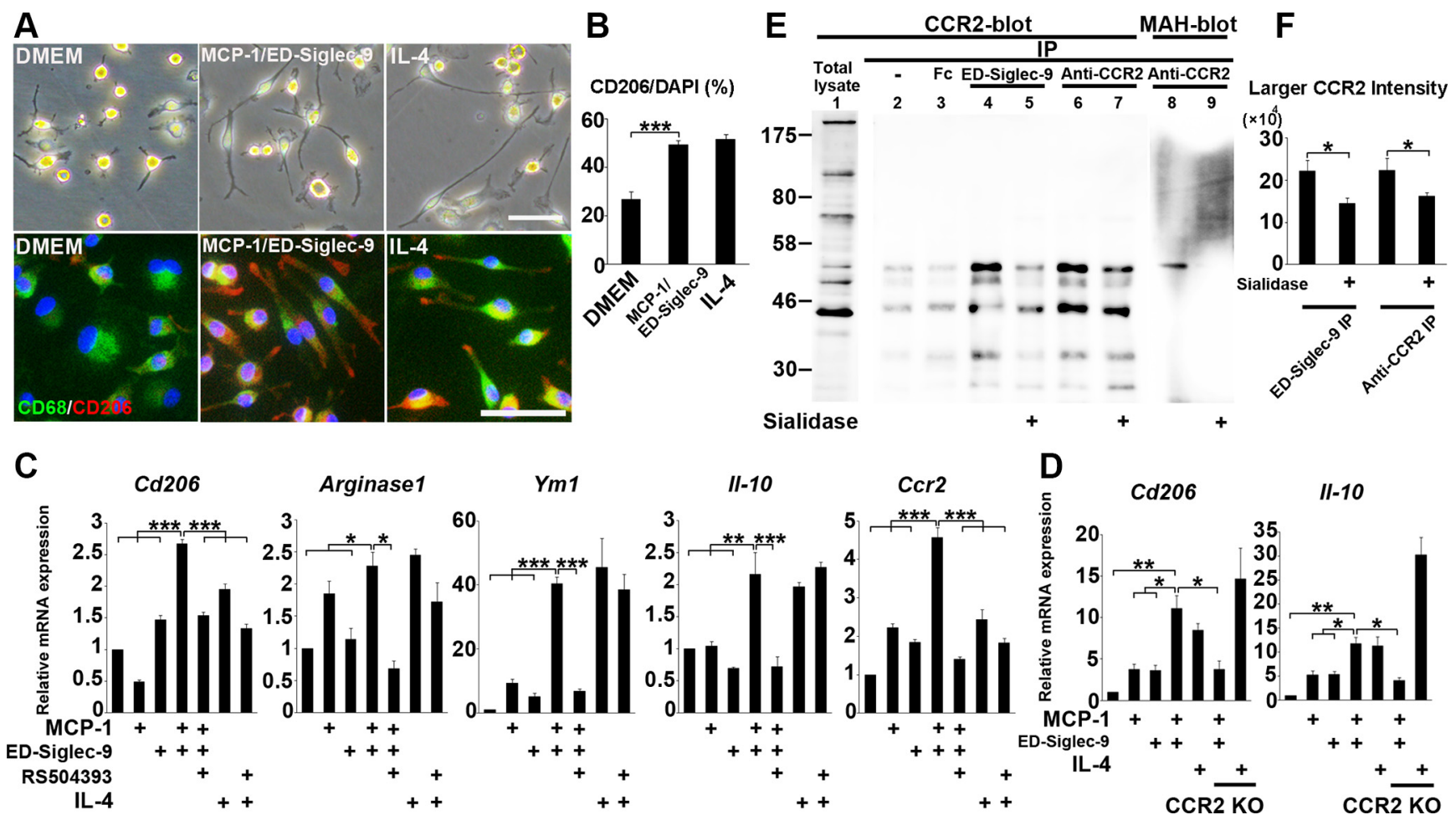

$11-10$

Figure 4. MCP-1 and ED-Siglec-9 synergistically induce M2-like macrophages via CCR2. A, Representative images of rat primary BMMs treated with DMEM, $100 \mathrm{ng} / \mathrm{mI}$ MCP-1/ED-Siglec-9, or 20 $\mathrm{ng} / \mathrm{ml} \mathrm{IL-4.} \mathrm{Top,} \mathrm{Optical-microscopy} \mathrm{images;} \mathrm{bottom,} \mathrm{CD206/CD68/DAPI} \mathrm{immunostaining.} \mathrm{B,} \mathrm{Quantification} \mathrm{of} \mathrm{CD206}{ }^{+} / \mathrm{DAPI}$ macrophages. AN0VA with Tukey's post hoc test ( $n=3$ separate experiments). C, D, Quantitative mRNA expression analysis of the indicated genes. BMMs treated with MCP-1/ED-Siglec-9 or IL-4. Results are relative to DMEM treatment. C, BMMs treated with or without CCR2 antagonist RS504393 (50 $\mu \mathrm{M})$. D, BMMs from adult CCR2 K0 mouse. CCR2 inhibition suppressed the MCP-1/ED-Siglec-9 mediated M2 differentiation but did not affect IL-4-mediated M2-induced signaling. ANOVA with Tukey's post hoc test ( $n=3$ separate experiments). $\boldsymbol{E}$, THP-1 cell lysates were immunoprecipitated using antibodies against ED-Siglec-9 or CCR2, and the precipitates were immunoblotted with anti-CCR2 antibody or MAH lectin (see Results). ED-Siglec-9 physically interacted with the larger, sialylated CCR2 (lane 4). Sialidase treatment suppressed the physical interaction between larger CCR2 and ED-Siglec-9 (lane 5). $\boldsymbol{F}$, Quantitative analysis showing that sialidase treatment inhibited the interaction of larger CCR2-ED-Siglec-9 (lane 5). ANOVA with Tukey's post hoc test $\left(n=3\right.$ separate experiments). Scale bar: $\boldsymbol{A}, 50 \mu \mathrm{m}$. Mean \pm SD $(\boldsymbol{B}, \boldsymbol{F})$ and mean \pm SEM $(\boldsymbol{C}, \boldsymbol{D}) .{ }^{*} p<0.05 ;{ }^{* *} p<0.01 ;{ }^{* * *} p<0.001$.

markers (Fig. 4C). In addition, MCP-1/ED-Siglec-9 promoted the $\mathrm{M} 2$ differentiation of BMMs isolated from wild-type, but not from CCR2 knock-out (KO), mice (Fig. $4 D$ ). These results demonstrated that CCR2 is required for the MCP-1/ED-Siglec9dependent induction of M2-like macrophages.

We next examined the physical interaction between CCR2 and ED-Siglec-9 using the human monocyte cell line THP-1, which expresses abundant endogenous CCR2. Immunoblot analysis revealed that THP-1 cells expressed multiple CCR2 proteins with different molecular weights (Fig. $4 E$; total lysate, lane 1). The immunoprecipitation of THP- 1 lysate with an anti-CCR2 antibody revealed two major species of CCR2 protein of 55 and $42 \mathrm{kDa}$ (lane 6). Maackia amurensis hemagglutinin (MAH) specifically recognizes carbohydrates containing $\alpha 2-3$-linked sialic acids, a major target of Siglec-9. We found that MAH bound to the larger CCR2 protein (MAH blot, lane 8), and sialidase treatment abolished the MAH-CCR2 binding (MAH blot, lane 9), indicating that the larger $55 \mathrm{kDa}$ protein represented the sialylated, mature CCR2 protein. Similarly, sialidase treatment decreased the amount of larger CCR2 immunoprecipitated with anti-CCR2 mAb (lane 7). Importantly, ED-Siglec-9 interacted preferentially with the larger CCR2 protein (lane 4), and sialidase treatment inhibited the larger CCR2-ED-Siglec-9 interaction (lane 5). These findings indicated that ED-Siglec-9 could interact with CCR2 and that this interaction depended on sialylated carbohydrates on CCR2. Quantification of the intensities of the sialylated mature CCR2 bands under each condition also confirmed that silalidase treatment reduced the amount of larger CCR2 immunoprecipitated with ED-Siglec-9 or anti-CCR2 mAb (Fig. 4F).

Neurorepair and neuroprotective activities of M2-like macrophages induced by MCP-1/ED-Siglec- 9

We next analyzed the trophic actions of the M2-like macrophages induced by MCP-1/ED-Siglec- 9 or IL-4 in neurite outgrowth and anti-apoptosis. CSPG, a major component of reactive glial scar surrounding the injured spinal cord, suppresses axonal regeneration (Silver and Miller, 2004). CGNs isolated from newborn rats extended neurites on PLL but not on CSPG. The direct addition of MCP-1/ED-Siglec-9 to CSPGs elicited little or no extension or anti-apoptosis activity (Fig. 5A-C). In contrast, the CMs derived from the M2-like cells induced by MCP-1/ED-Siglec-9 or IL-4 similarly extended the CGNs neurites on CSPG (Fig. $5 A, B$ ). Furthermore, these CMs significantly suppressed the CSPG-induced apoptosis of CGNs (Fig. 5A,C). qPCR analysis revealed that the M2-like BMMs induced by MCP-1/ED-Siglec-9 exhibited increased expressions of various types of neurotrophic and growth factors (Fig. 5D). Together, these results demonstrate that the M2-like cells induced by MCP-1/ED-Siglec-9 elicit significant neurorepair and protective activities that override the antineuroregenerative activity of CSPG.

SHED-CM lacking both MCP-1 and ED-Siglec-9 fails to induce $\mathrm{M} 2$ or to restore locomotor function after SCI We next examined the role of MCP-1 and ED-Siglec-9 in the SHED-CM-mediated functional recovery after SCI. Both 


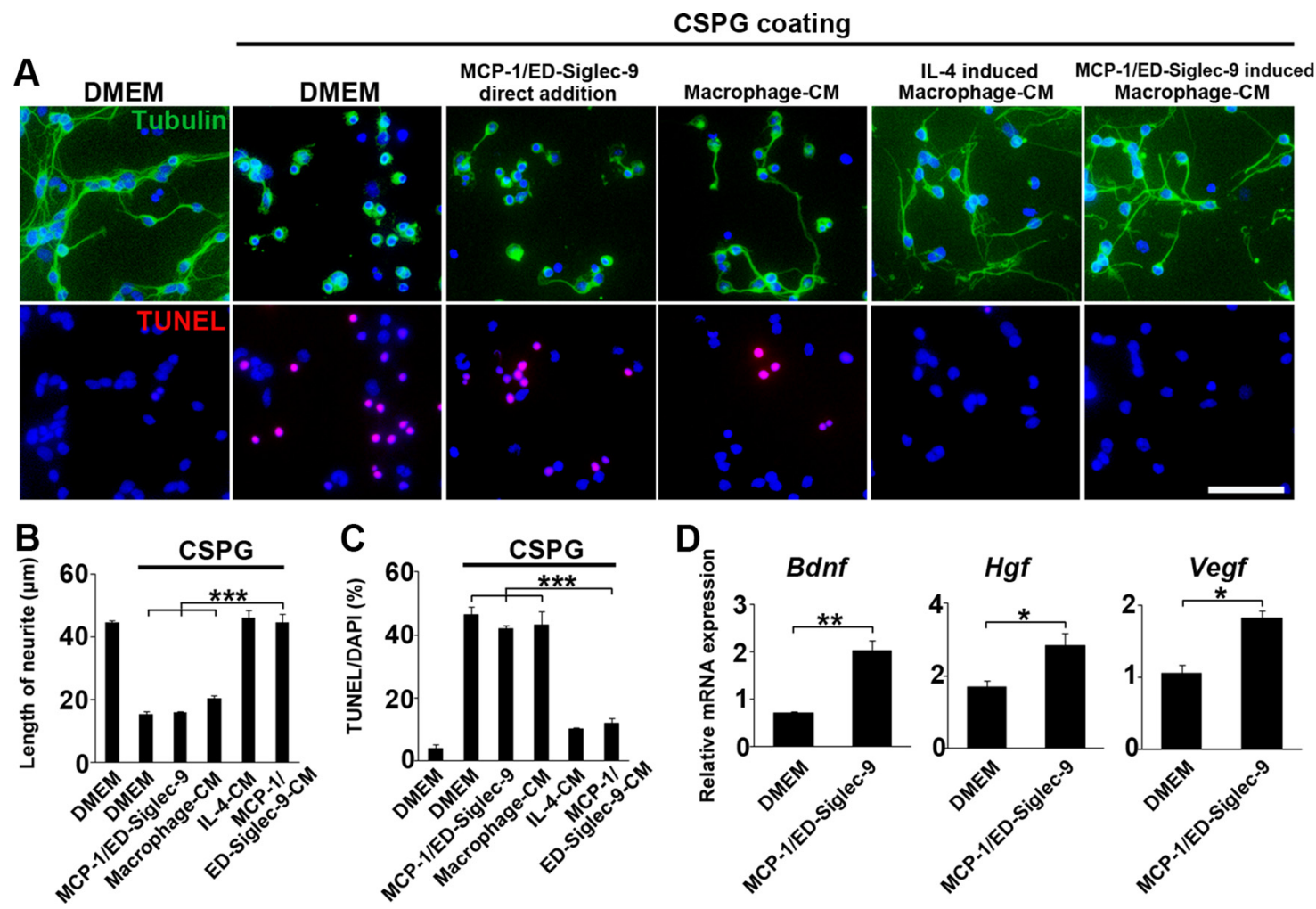

Figure 5. MCP-1/ED-Siglec-9-induced M2 exhibits neurorepairing and neuroprotective activities in vitro. A, Rat primary CGNs were placed on PLL-coated or PLL/CSPG-coated (300 ng/ml) plates and incubated for $24 \mathrm{~h}$ with serum-free DMEM, SHED-CM, $100 \mathrm{ng} / \mathrm{ml}$ MCP-1/ED-Siglec-9, or rat BMM-CMs and stained for tubulin or TUNEL. BMM-CMs were prepared by culturing in each condition (DMEM, IL-4, or MCP-1/ED-Siglec-9). B, C, Quantification of CGN neurite length and TUNEL ${ }^{+}$apoptotic cells. Notably, CGNs plated with BMM-CM harvested from IL-4 or MCP-1/ED-Siglec-9-induced M2-like cells significantly extended their neurites and showed suppressed apoptosis in CSPG-coated wells, whereas the direct addition of MCP-1/ED-Siglec-9 to CGNs did not cause these effects. $\boldsymbol{D}$, Quantification of the mRNA expression of the indicated genes in rat BMMs. M2-like macrophages induced by MCP-1/ED-Siglec-9 showed significantly increased expressions of neurotrophic/growth factors, such as Bdnf, hepatocyte growth factor (Hgf), and Vegf. ANOVA with Tukey's post hoc test ( $n=3$ separate experiments). Scale bar: $\boldsymbol{A}, 50 \mu \mathrm{m}$. Mean \pm SD (B, C) and mean \pm SEM (D). ${ }^{*} p<$ $0.05 ;{ }^{* *} p<0.01 ;{ }^{* *} p<0.001$

MCP-1 and ED-Siglec-9 were specifically immunodepleted from SHED-CM (dSHED-CM; Fig. 6A). Eight weeks after SCI, rats treated with dSHED-CM exhibited less functional recovery (Fig. $6 B$ ) and more tissue damage than rats given whole SHED-CM, as indicated by the residual areas of white and gray matter and of 5-HT fibers (Fig. 6C,D). Seventy-two hours after SCI, rats treated with dSHED-CM did not show the induction of IL-10-producing $\mathrm{CD}^{2} 6^{+}$M2-like macrophages or the increased expression of M2 genes (Fig. $6 E-H$ ), whereas the depletion of IL-6 from SHED-CM (-IL-6) had little or no effect on the M2 production (Fig. 6E). These results demonstrated that MCP-1 and EDSiglec- 9 are required for the SHED-CM-mediated M2 induction and functional recovery from SCI in vivo.

MCP-1/ED-Siglec-9 activates an anti-inflammatory M2 response in vivo and promotes functional recovery after SCI Next, we examined the therapeutic benefit of MCP-1/EDSiglec- 9 treatment in promoting functional recovery after rat SCI. Eight weeks after SCI, rats treated with MCP-1/ED-Siglec-9 exhibited less tissue loss and more 5-HT-positive fibers in the lesion epicenter than the controls, were able to walk, and placed weight on their hindlimbs (Fig. 7A-E). The MCP-1/ED-Siglec-9 treatment suppressed proinflammatory cytokine expression but increased the levels of anti-inflammatory cytokines and M2 markers and Ccr2 (Fig. $7 F$ ). The number of CD206 ${ }^{+}$M2-like cells in the rats treated with MCP-1/ED-Siglec- 9 was three times that in the controls (Fig. 7G-I). Immunoblot analysis showed that the level of CD206 expression in the spinal cord treated with
MCP-1/ED-Siglec-9 was twice that in the control (Fig. 7J, K). These results indicated that MCP-1/ED-Siglec- 9 induces antiinflammatory/tissue-repairing M2-like macrophages and promotes substantial functional recovery after SCI.

MCP-1/ED-Siglec-9-stimulated M2 induction required for the functional recovery of rat $\mathrm{SCI}$

Finally, we examined whether the M2-like microglia/macrophages induced by MCP-1/ED-Siglec-9/CCR2 signaling played a central role in the functional recovery of rat SCI. We prevented the increase in M2-like cells by inhibiting the CCR2 function. The genetic deletion of CCR2 is reported to abolish the recruitment of all monocyte/macrophage lineages, which would not be useful for examining the role of M2-like cells in SCI improvement (Little et al., 2014). Therefore, we inactivated the CCR2 function by RS504393 treatment $36 \mathrm{~h}$ after SCI, when most of the microglia/macrophages have been recruited. RS504393 treatment suppressed the induction of CD206 ${ }^{+}$ M2-like cells by SHED-CM or MCP-1/ED-Siglec- 9 treatment without affecting the number of $\mathrm{Iba}^{+}{ }^{+}$cells (Fig. $8 A-C$ ). Furthermore, rats treated with RS504393 exhibited less functional recovery (Fig. $8 D$ ) and more tissue damage than rats given whole SHED-CM or MCP-1/ED-Siglec- 9 , as indicated by the residual areas of white and gray matter and 5-HT fibers (Fig. $8 E-G)$. Together, these results demonstrated that MCP-1/EDSiglec-9-induced M2-like macrophages are essential for the functional recovery from rat SCI. 


\begin{tabular}{|c|c|c|c|}
\hline & MCP-1 (pg/m l) & Siglec-9 (pg/m l) & IL-6 (pg/m l) \\
\hline SHED-CM (bead only) & $\#_{383.66 \pm 19.96}$ & $\#_{1229.85 \pm 152.07}$ & $43.21 \pm 0.47$ \\
\hline $\begin{array}{c}\text { dSHED-CM } \\
\text { (bead+MCP-1/Siglec-9 A bs) }\end{array}$ & $5.00 \pm 0.84$ & ND & $43.86 \pm 0.94$ \\
\hline
\end{tabular}

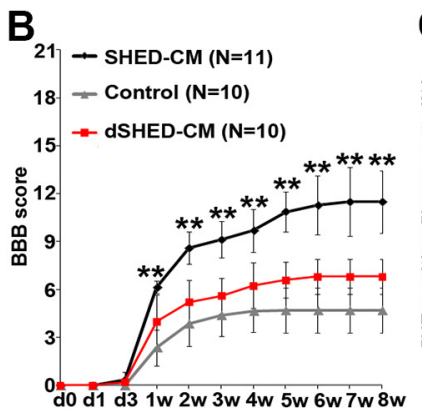

Weeks

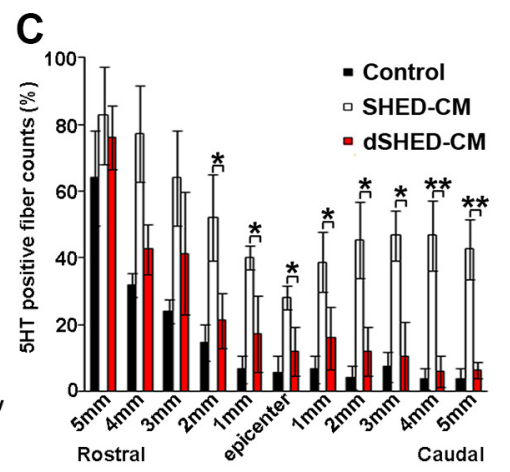

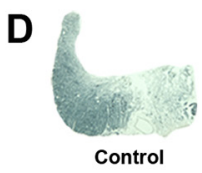
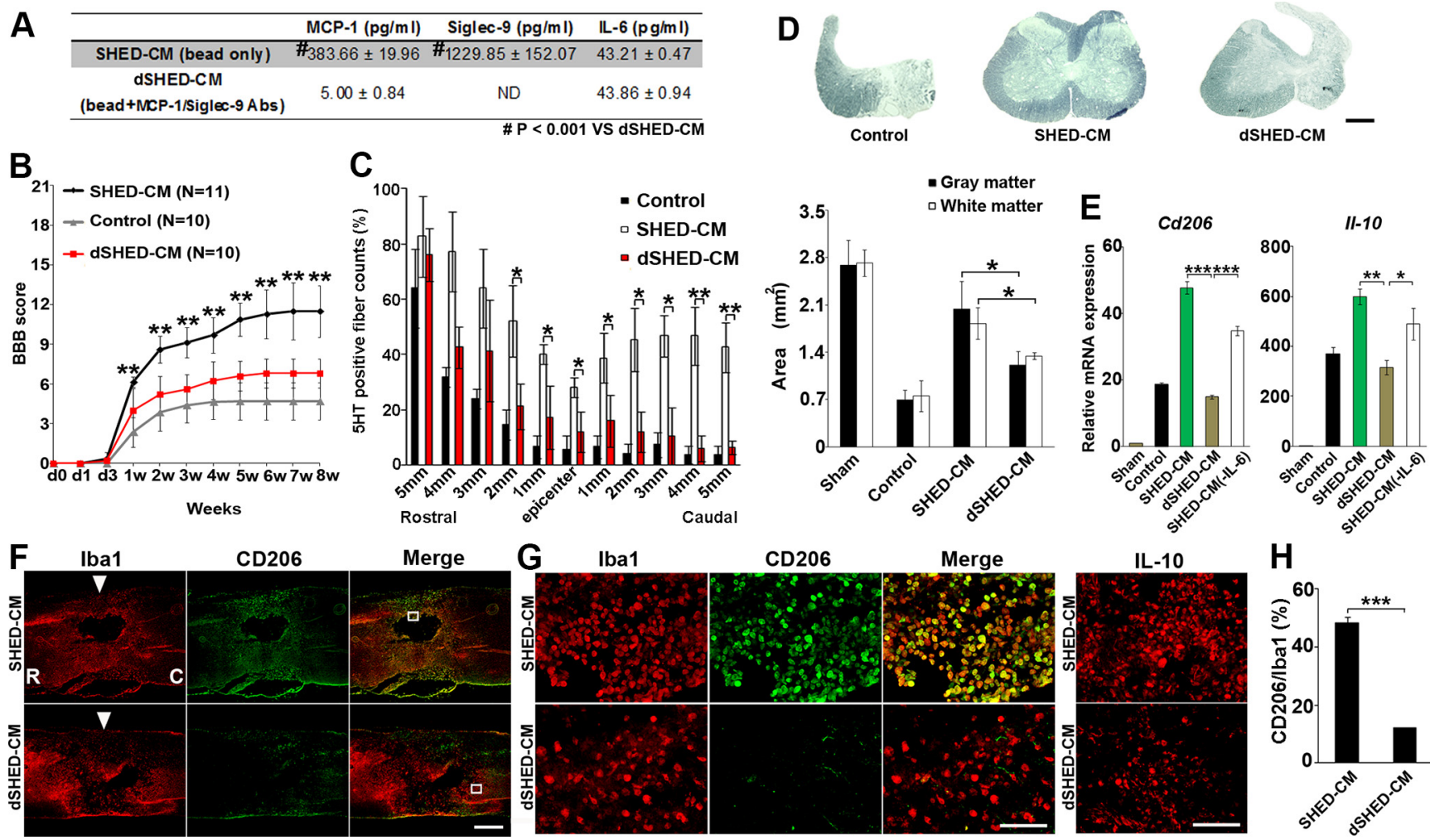

Figure 6. MCP-1 and ED-Siglec-9 are essential for SHED-CM-mediated functional recovery after SCI. $\boldsymbol{A}$, Quantification of MCP-1, Siglec-9, and IL-6 in dSHED-CM. B, Recovery of hindlimb locomotion after SCI. SHED-CM, $n=11$; DMEM, $n=10$; dSHED-CM, $n=10$. ANOVA with Tukey's post hoc test. C, Quantification of 5 -HT-positive nerve fibers from $5 \mathrm{~mm}$ rostral to $5 \mathrm{~mm}$ caudal. ANOVA with Tukey's post hoc test ( $n=3$ rats per group and 5 sections per animal). D, Sudan black B staining of axial spinal cord sections 3 mm caudal from the epicenter 8 weeks after $S C l$, and quantification of gray and white matter areas $3 \mathrm{~mm}$ caudal from epicenter. ANOVA with Tukey's post hoc test ( $n=3$ rats per group). $\boldsymbol{E}, \mathrm{qPCR}$ analysis of the indicated genes in spinal cord treated with dSHED-CM $72 \mathrm{~h}$ after SCI. Results are expressed relative to the level in the sham-operated model. ANOVA with Tukey's post hoc test ( $n=3$ rats per group). $\boldsymbol{F}$ - $\boldsymbol{H}$, Representative images of sagittal spinal cord sections and quantification of $\mathrm{CD} 206^{+} / \mathrm{lba} 1^{+} \mathrm{M}$--like cells treated with dSHED-CM $72 \mathrm{~h}$ after SCI. R, Rostral; $C$, caudal; arrowhead, epicenter. G, Left, High-power view of the boxed area in $\boldsymbol{F}$. Right, Images of the IL-10 immunostaining. $\boldsymbol{H}$, Quantitative analysis. Unpaired two-tailed Student's $t$ test $(n=3$ rats per group and 5 sections per animal). Scale bars: $\boldsymbol{D}, \boldsymbol{F}, 500 \mu \mathrm{m} ; \boldsymbol{G}, 100 \mu \mathrm{m}$. Mean \pm SD $(\boldsymbol{B}-\boldsymbol{D}, \boldsymbol{H})$ and mean \pm SEM $(\boldsymbol{E}) .{ }^{*} p<0.05 ;{ }^{* *} p<0.01 ;{ }^{* * *} p<0.001$.

\section{Discussion}

We reported previously that SHED transplantation promotes remarkable functional recovery of the transected rat spinal cord (Sakai et al., 2012). In the present study, we extended our previous findings by identifying tissue-repairing factors secreted from the SHEDs.

We first found that the transplantation of SHEDs or intrathecal administration of SHED-CM promoted remarkable functional recovery in rats after SCI. This recovery was associated with an immunoregulatory activity that induced anti-inflammatory M2-like macrophages. We then identified a previously unrecognized set of M2 inducers, MCP-1 and ED-Siglec-9, by secretome analysis of the SHED-CM. Neither MCP-1 nor ED-Siglec-9 alone could recapitulate the SHED-CM activity. Notably, however, the combination of MCP-1 and ED-Siglec-9 recapitulated the SHED-CM activity for M2-like macrophage induction and promoted substantial functional recovery from rat SCI. Together, our data suggest that MCP-1/ED-Siglec- 9 may provide therapeutic benefits for treating acute-phase SCI by activating endogenous tissue-repairing mechanisms.

MSCs exhibit unique immunoregulatory properties that contribute to their tissue-repairing activities. It was reported previously that BMSC transplantation into SCI or brain ischemia models leads to M2 induction (Ohtaki et al., 2008; Nakajima et al., 2012). However, here we found that the administration of BMSC-CM induced no or little M2-like cells. This may be explained by the restricted conditions that are required for BMSC-mediated M2 differentia- tion; both the presensitization of BMSCs by proinflammatory factors, such as IFN- $\gamma$, TNF- $\alpha$, and LPS, and direct cell-to-cell contact are prerequisite for the BMSC-mediated M2-like macrophage induction (Németh et al., 2009; Singer and Caplan, 2011). These stimulations increase the BMSC expression of cyclooxygenase 2 and indoleamine 2,3-dioxygnase, and the products of these enzymes, prostaglandin E2 and kynurenine, promote the repolarization of proinflammatory M1-like to anti-inflammatory M2-like macrophages (Le Blanc and Mougiakakos, 2012). In contrast, SHEDs induced M2-like cells through the secretion of MCP-1/ED-Siglec-9. We found similar expressions of the full-length transmembrane form of Siglec-9 in the cell lysates of fibroblasts, BMSCs, and SHEDs; however, the secreted ED-Siglec-9 was uniquely present in the SHED-CM. This finding suggests that SHED-CM, but not BMSC$\mathrm{CM}$, contains the protease(s) responsible for the shedding of Siglec-9. Thus, although M2 induction is an important common strategy in MCS-mediated tissue repair, the mechanisms for M2 induction, and thus the M2-related therapeutic activities, vary for different stem cell types.

SCI involves concurrent and interacting pathological processes; therefore, its treatment must have multifaceted effects (Schwab et al., 2006; Rowland et al., 2008; Snyder and Teng, 2012). We found that treatment with MCP-1/ED-Siglec- 9 alone established anti-inflammatory M2 conditions, reduced tissue damage, preserved the descending 5-HT-positive axons, and promoted functional recovery. Notably, MCP-1/ED-Siglec-9 had lit- 


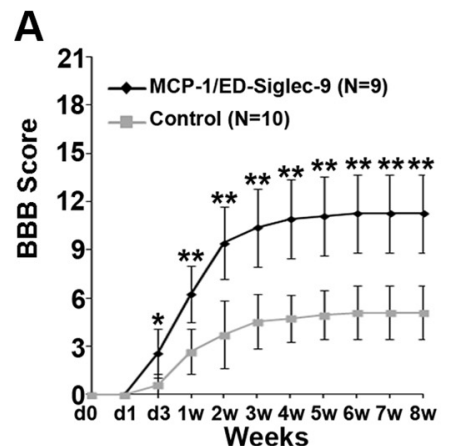

F

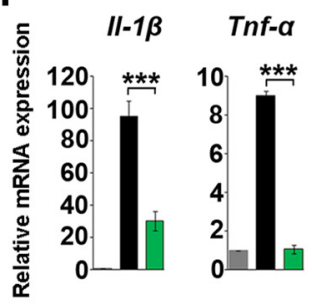

Cd206 Arginase1 $/ /-10$

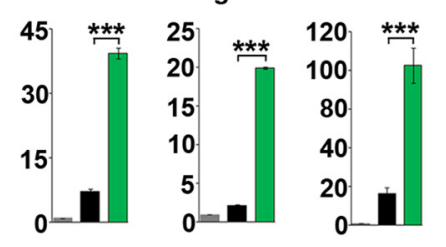

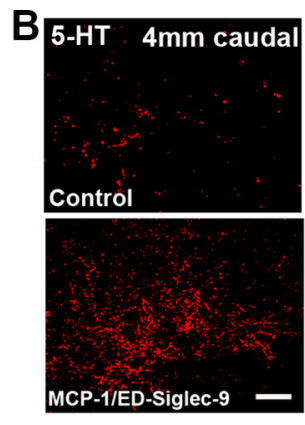
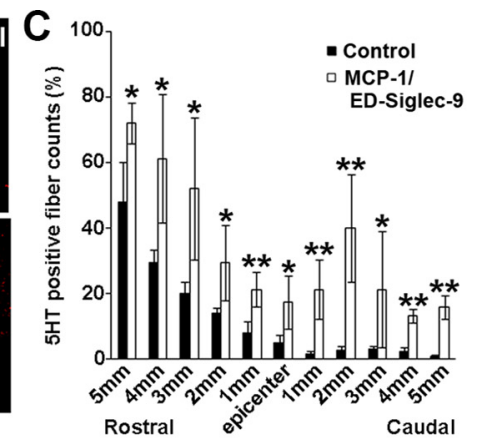

G
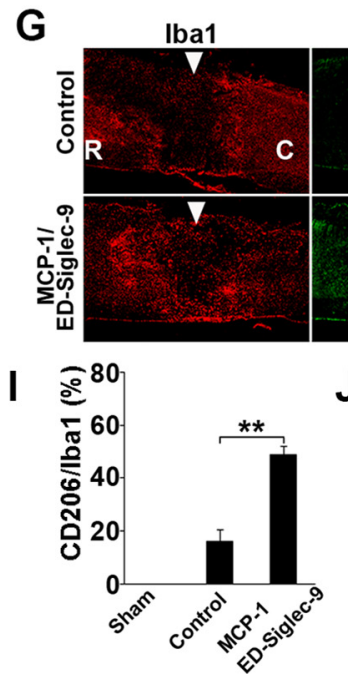

9. Control

0

ED-Siglec-9

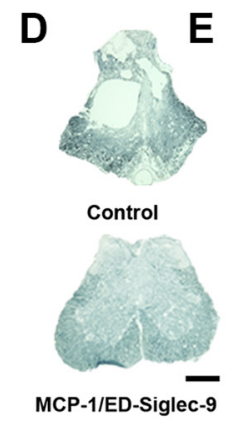

E

Gray matter

$\checkmark$ White matter

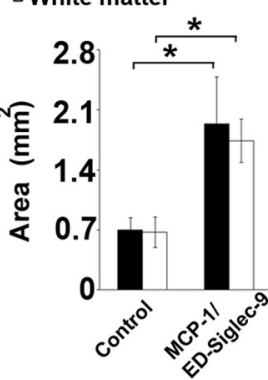

CD206

H CD206/LL-10

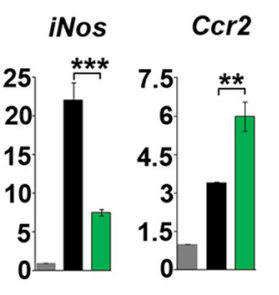

Tgf- $\beta 1$

15 ***

6 口 MCP-1/

$3 . \quad$ ED-Siglec-9
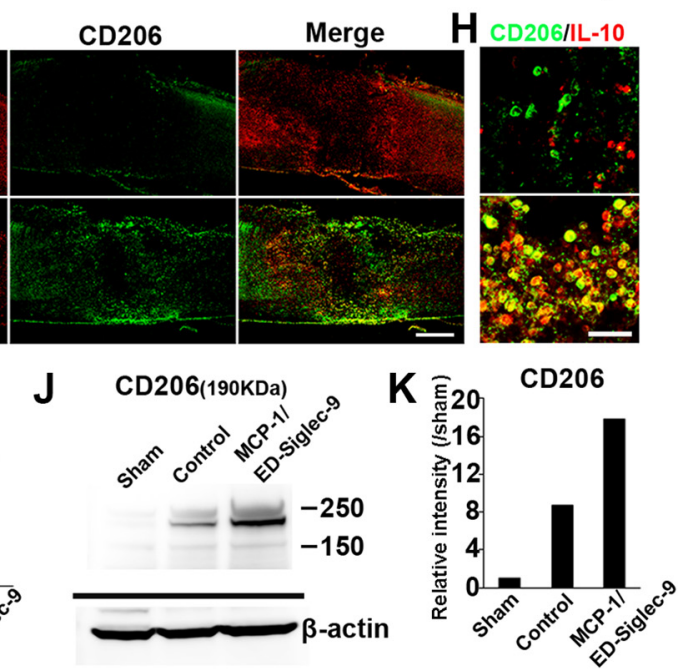

Figure 7. MCP-1/ED-Siglec-9 activates an anti-inflammatory M2 response and promotes functional recovery after SCl. $\boldsymbol{A}$, Recovery of hindlimb locomotion after SCI. PBS, $n=10$; $M C P-1 / E D-$ Siglec-9, $n=9$. ANOVA with Tukey's post hoc test. $\boldsymbol{B}$, Immunohistological images of 5-HT-positive nerve fibers in sagittal sections of the injured spinal cord 4 mm caudal from the epicenter, 8 weeks after SCl. C, Quantification of 5-HT-positive nerve fibers from $5 \mathrm{~mm}$ rostral to $5 \mathrm{~mm}$ caudal. Unpaired two-tailed Student's $t$ test ( $n=3$ rats per group). $\boldsymbol{D}, \boldsymbol{E}$, Sudan black B staining of axial spinal cord sections $3 \mathrm{~mm}$ caudal from the epicenter 8 weeks after $\mathrm{SCl}$, and quantification of gray and white matter areas $3 \mathrm{~mm}$ caudal from epicenter. ANOVA with Tukey's post hoc test ( $n=3$ rats per group). $\boldsymbol{F}$, Levels of the indicated mRNAs in the spinal cord $72 \mathrm{~h}$ after $\mathrm{SCl}$. ANOVA with Tukey's post hoc test ( $n=3$ rats per group). $\boldsymbol{G}, \boldsymbol{H}$, Immunohistological images of sagittal spinal cord sections $72 \mathrm{~h}$ after SCl. Left, Treatment; top, antibodies used. I, Quantification of CD206 ${ }^{+} / \mathrm{Iba} 1^{+}$cells in the spinal cord. An unpaired two-tailed Student's $t$ test $(n=3$ rats per group and 5 sections per animal). $J$, Immunoblot analysis for CD206 protein $72 \mathrm{~h}$ after SCl. $\boldsymbol{K}$, Expression intensity analysis of CD206 protein bands. Scale bars: $\boldsymbol{D}, \boldsymbol{G}, 500 \mu \mathrm{m} ; \boldsymbol{B}, \boldsymbol{H}, 100 \mu \mathrm{m}$. Mean \pm SD $(\boldsymbol{A}, \boldsymbol{C}, \boldsymbol{E}, \boldsymbol{I})$ and mean $\pm \mathrm{SEM}(\boldsymbol{F})$. ${ }^{*} p<0.05 ;{ }^{* *} p<0.01 ;{ }^{* * *} p<0.001$.

tle or no direct trophic effect on the primary neurons (CGNs); however, the M2-like BMMs induced by them promoted neurite extension in these neurons and suppressed their CSPG-induced apoptosis. Furthermore, the BMMs treated with MCP-1/EDSiglec-9 exhibited increased expressions of various neurotrophic factors. All these data collectively suggest that M2-like cells induced by MCP-1/ED-Siglec-9 exert multifaceted neurorepairing activities besides suppressing inflammation, thus enabling MCP1/ED-Siglec-9 alone to promote functional recovery after SCI.

MCP-1 is known to contribute strongly to the proinflammatory M1 response by recruiting macrophages to inflammation sites (Tsou et al., 2007). Thus, the targeted neutralization of MCP-1 activity has been examined in many clinical trials for acute and chronic inflammatory disease treatments (Shachar and Karin, 2013). In contrast, we here present a unique anti-inflammatory function for MCP-1, in which it acts via its cognate receptor CCR2, in concert with EDSiglec-9, to induce the M2-like macrophages. Although MCP-1 treatment alone is reported to be sufficient to induce the M2-like macrophage phenotype (Roca et al., 2009), we were unable to confirm this MCP-1 function using BMM-derived native macrophages. In this report, we found that a synergistic action of MCP-1 and ED-Siglec-9 was required to induce M2-like macrophages.

Sialic acids are terminal acidic monosaccharides that influence the chemical and biological features of glycoconjugates.
Their removal, catalyzed by sialidase, modulates various biological processes through conformational changes and through the creation or loss of binding sites for functional molecules (Miyagi and Yamaguchi, 2012). In this study, we found that sialidase treatment completely abolished the M2-like property of BMMs, indicating that sialic acids play a substantial role in determining the characteristics of monocytes/macrophages. Siglec-9 is a type-I transmembrane protein that functions as a receptor; Siglec-9 negatively regulates immune cell function through its cytoplasmic immunoreceptor tyrosine-based inhibitory motif (Linnartz and Neumann, 2013), although a role for its secreted ectodomain, ED-Siglec-9, has not been identified. Here we showed that secreted ED-Siglec-9 functions as a ligand to modulate the ability of MCP-1 to induce M2-like macrophages. Although the detailed mechanism of the MCP-1/ED-Siglec-9-mediated M2 differentiation remains to be elucidated in future studies, our present findings suggest that ED-Siglec- 9 binds to sialylated carbohydrates on CCR2, thereby modifying the MCP-1 signaling through CCR2.

Together with our previous reports (Sakai et al., 2012; Yamagata et al., 2013), we have demonstrated three modes of therapeutic intervention using tooth-derived stem cells for the treatment of acute CNS injury: cell transplantation, CM administration, and factor administration. Cell-transplantation therapy 

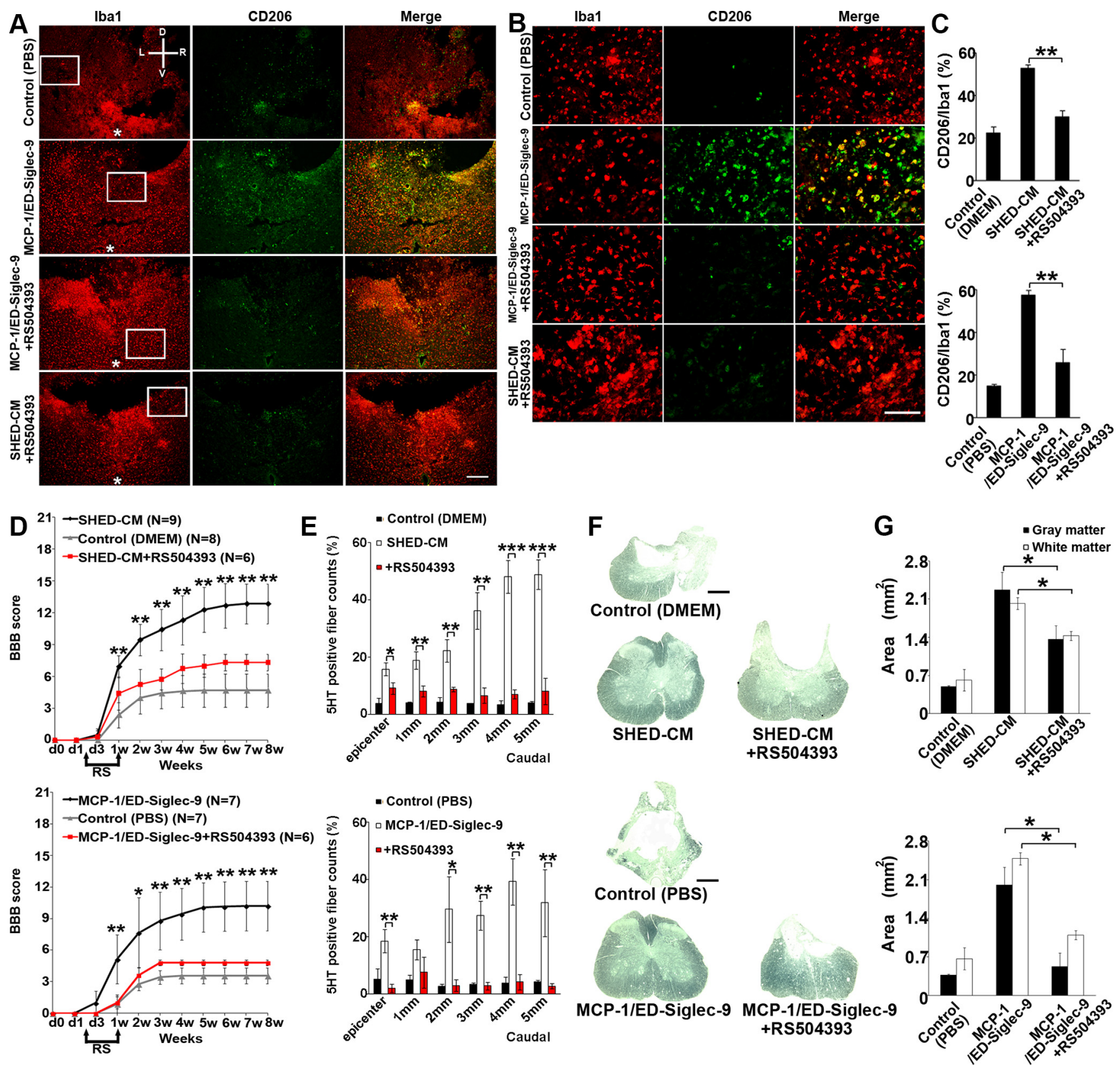

Figure 8. Effects of CCR2 depletion on MCP-1/ED-Siglec-9-stimulated M2 induction. A selective inhibitor for CCR2, RS504393 (2 mg/kg), was given to rats orally every $12 \mathrm{~h}$ for $1 \mathrm{week}$ starting $36 \mathrm{~h}$ after SCI. $\boldsymbol{A}, \boldsymbol{B}$, Representative immunohistological images of axial plane spinal cord sections $3 \mathrm{~mm}$ caudal to the epicenter $72 \mathrm{~h}$ after SCI. Left, Treatment; top, antibodies. D, Dorsal; $\mathrm{V}$, ventral; L, left; $\mathrm{R}$, right. Asterisks in the left indicate the central canal of the spinal cord. $\boldsymbol{B}$, High-power view of the boxed area in $A$. C, Quantitative analysis. ANOVA with Tukey's post hoc test ( $\mathrm{n}=3$ rats per group and 5 sections per animal). SHED-CM or MCP-1/ED-Siglec-9 failed to induce CD206 ${ }^{+}$M2-like cells in the SCI rat treated with RS504393. D, Recovery of hindlimb locomotion after SCI. Top, SHED-CM, $n=9 ;$ DMEM, $n=8 ;$ SHED-CM + RS504393, $n=6$. Bottom, MCP-1/ED-Siglec-9, $n=7 ;$ PBS, $n=7 ;$ MCP-1/ED-Siglec-9 + RS504393, $n=6$. ANOVA with Tukey's post hoc test. E, Quantification of 5-HT-positive nerve fibers from the epicenter to $5 \mathrm{~mm}$ caudal. ANOVA with Tukey's post hoc test ( $n=3$ rats per group and 5 sections per animal). $\boldsymbol{F}, \mathbf{G}$, Sudan black B staining of axial spinal cord sections $3 \mathrm{~mm}$ caudal to the epicenter 8 weeks after $\mathrm{SCl}$, and quantification of gray and white matter areas $3 \mathrm{~mm}$ caudal to the epicenter. ANOVA with Tukey's post hoc test ( $\mathrm{n}=3$ rats per group). Scale bars: $\boldsymbol{A}, 200 \mu \mathrm{m} ; \boldsymbol{B}, 100 \mu \mathrm{m} ; \boldsymbol{F}, 500 \mu \mathrm{m}$. Mean \pm SD. ${ }^{*} p<0.05 ;{ }^{* *} p<0.01 ;{ }^{* *} p<0.001$. RS, RS504393.

is a promising treatment for SCI (de Almeida et al., 2011; Sakai et al., 2012; Taghipour et al., 2012); however, for clinical use, the cells must be expanded by a reliable cell culture system that produces sufficient cell numbers for clinical effects, while also meeting safety requirements, and tumorigenesis and strong immune reactions must be avoided. In contrast, the administration of preserved CM is convenient for immediate application and minimizes the surgical invasiveness. Theoretically, allogenic CM can be used without immune rejection. However, for clinical use, the factors providing therapeutic benefits must be isolated from ad- verse factors in $\mathrm{CM}$, including residual cell culture materials. Moreover, the pharmacokinetic analysis of $\mathrm{CM}$, which contains multiple factors, is extremely difficult. Therefore, the administration of defined factors eliciting the benefits of CM may be the most clinically practical strategy.

In conclusion, we identified a novel set of M2 inducers, MCP-1 and ED-Siglec-9, from SHED-CM. The induced M2-like cells activated multifaceted endogenous neurorepair mechanisms, by which the locomotor function of SCI rats was substantially restored. Our study revealed that MSC-derived secreted 
factors directly convert the proinflammatory conditions prevalent in the damaged CNS to tissue-repairing ones by modulating the microglia/macrophage phenotype.

\section{References}

Ahmed Z, Mazibrada G, Seabright RJ, Dent RG, Berry M, Logan A (2006) TACE-induced cleavage of NgR and p75NTR in dorsal root ganglion cultures disinhibits outgrowth and promotes branching of neurites in the presence of inhibitory CNS myelin. FASEB J 20:1939-1941. CrossRef Medline

Ando M, Tu W, Nishijima K, Iijima S (2008) Siglec-9 enhances IL-10 production in macrophages via tyrosine-based motifs. Biochem Biophys Res Commun 369:878-883. CrossRef Medline

Arthur A, Rychkov G, Shi S, Koblar SA, Gronthos S (2008) Adult human dental pulp stem cells differentiate toward functionally active neurons under appropriate environmental cues. Stem Cells 26:1787-1795. CrossRef Medline

Basso DM, Beattie MS, Bresnahan JC (1995) A sensitive and reliable locomotor rating scale for open field testing in rats. J Neurotrauma 12:1-21. CrossRef Medline

Chaballe L, Schoenen J, Franzen R (2011) Placental growth factor: a tissue modelling factor with therapeutic potentials in neurology? Acta Neurol Belg 111:10-17. Medline

Colton CA, Gilbert DL (1987) Production of superoxide anions by a CNS macrophage, the microglia. FEBS Lett 223:284-288. CrossRef Medline

Crocker PR, Paulson JC, Varki A (2007) Siglecs and their roles in the immune system. Nat Rev Immunol 7:255-266. CrossRef Medline

David S, Kroner A (2011) Repertoire of microglial and macrophage responses after spinal cord injury. Nat Rev Neurosci 12:388-399. CrossRef Medline

Davies JE, Tang X, Denning JW, Archibald SJ, Davies SJ (2004) Decorin suppresses neurocan, brevican, phosphacan and NG2 expression and promotes axon growth across adult rat spinal cord injuries. Eur J Neurosci 19:1226-1242. CrossRef Medline

de Almeida FM, Marques SA, Ramalho Bdos S, Rodrigues RF, Cadilhe DV, Furtado D, Kerkis I, Pereira LV, Rehen SK, Martinez AM (2011) Human dental pulp cells: a new source of cell therapy in a mouse model of compressive spinal cord injury. J Neurotrauma 28:1939-1949. CrossRef Medline

Dewerchin M, Carmeliet P (2012) PlGF: a multitasking cytokine with disease-restricted activity. Cold Spring Harb Perspect Med 2:pii:a011056. CrossRef Medline

Doyle KP, Yang T, Lessov NS, Ciesielski TM, Stevens SL, Simon RP, King JS, Stenzel-Poore MP (2008) Nasal administration of osteopontin peptide mimetics confers neuroprotection in stroke. J Cereb Blood Flow Metab 28:1235-1248. CrossRef Medline

Edwards JP, Zhang X, Frauwirth KA, Mosser DM (2006) Biochemical and functional characterization of three activated macrophage populations. J Leukoc Biol 80:1298-1307. CrossRef Medline

Esper RM, Pankonin MS, Loeb JA (2006) Neuregulins: versatile growth and differentiation factors in nervous system development and human disease. Brain Res Rev 51:161-175. CrossRef Medline

Fitch MT, Doller C, Combs CK, Landreth GE, Silver J (1999) Cellular and molecular mechanisms of glial scarring and progressive cavitation: in vivo and in vitro analysis of inflammation-induced secondary injury after CNS trauma. J Neurosci 19:8182-8198. Medline

Geisler C, Jarvis DL (2011) Effective glycoanalysis with Maackia amurensis lectins requires a clear understanding of their binding specificities. Glycobiology 21:988-993. CrossRef Medline

Gordon S, Martinez FO (2010) Alternative activation of macrophages: mechanism and functions. Immunity 32:593-604. CrossRef Medline

Gronthos S, Mankani M, Brahim J, Robey PG, Shi S (2000) Postnatal human dental pulp stem cells (DPSCs) in vitro and in vivo. Proc Natl Acad Sci U S A 97:13625-13630. CrossRef Medline

Harvey S, Hull K (2003) Neural growth hormone: an update. J Mol Neurosci 20:1-14. CrossRef Medline

Hashimoto M, Sun D, Rittling SR, Denhardt DT, Young W (2007) Osteopontin-deficient mice exhibit less inflammation, greater tissue damage, and impaired locomotor recovery from spinal cord injury compared with wild-type controls. J Neurosci 27:3603-3611. CrossRef Medline

Horn KP, Busch SA, Hawthorne AL, van Rooijen N, Silver J (2008) Another barrier to regeneration in the CNS: activated macrophages induce extensive retraction of dystrophic axons through direct physical interactions. J Neurosci 28:9330-9341. CrossRef Medline

Hsu JY, McKeon R, Goussev S, Werb Z, Lee JU, Trivedi A, Noble-Haeusslein LJ (2006) Matrix metalloproteinase-2 facilitates wound healing events that promote functional recovery after spinal cord injury. J Neurosci 26 : 9841-9850. CrossRef Medline

Imagama S, Sakamoto K, Tauchi R, Shinjo R, Ohgomori T, Ito Z, Zhang H, Nishida Y, Asami N, Takeshita S, Sugiura N, Watanabe H, Yamashita T, Ishiguro N, Matsuyama Y, Kadomatsu K (2011) Keratan sulfate restricts neural plasticity after spinal cord injury. J Neurosci 31:17091-17102. CrossRef Medline

Inoue T, Sugiyama M, Hattori H, Wakita H, Wakabayashi T, Ueda M (2013) Stem cells from human exfoliated deciduous tooth-derived conditioned medium enhance recovery of focal cerebral ischemia in rats. Tissue Eng Part A 19:24-29. CrossRef Medline

Jin K, Mao XO, Sun Y, Xie L, Greenberg DA (2002) Stem cell factor stimulates neurogenesis in vitro and in vivo. J Clin Invest 110:311-319. CrossRef Medline

Kieran D, Sebastia J, Greenway MJ, King MA, Connaughton D, Concannon CG, Fenner B, Hardiman O, Prehn JH (2008) Control of motoneuron survival by angiogenin. J Neurosci 28:14056-14061. CrossRef Medline

Kigerl KA, Gensel JC, Ankeny DP, Alexander JK, Donnelly DJ, Popovich PG (2009) Identification of two distinct macrophage subsets with divergent effects causing either neurotoxicity or regeneration in the injured mouse spinal cord. J Neurosci 29:13435-13444. CrossRef Medline

Király M, Porcsalmy B, Pataki A, Kádár K, Jelitai M, Molnár B, Hermann P, Gera I, Grimm WD, Ganss B, Zsembery A, Varga G (2009) Simultaneous PKC and cAMP activation induces differentiation of human dental pulp stem cells into functionally active neurons. Neurochem Int 55:323332. CrossRef Medline

Kitamura K, Fujiyoshi K, Yamane J, Toyota F, Hikishima K, Nomura T, Funakoshi H, Nakamura T, Aoki M, Toyama Y, Okano H, Nakamura M (2011) Human hepatocyte growth factor promotes functional recovery in primates after spinal cord injury. PLoS One 6:e27706. CrossRef Medline

Le Blanc K, Mougiakakos D (2012) Multipotent mesenchymal stromal cells and the innate immune system. Nat Rev Immunol 12:383-396. CrossRef Medline

Lecouter J, Lin R, Ferrara N (2004) EG-VEGF: a novel mediator of endocrine-specific angiogenesis, endothelial phenotype, and function. Ann N Y Acad Sci 1014:50-57. CrossRef Medline

Lee HK, Seo IA, Park HK, Park YM, Ahn KJ, Yoo YH, Park HT (2007) Nidogen is a prosurvival and promigratory factor for adult Schwann cells. J Neurochem 102:686-698. CrossRef Medline

Leong WK, Henshall TL, Arthur A, Kremer KL, Lewis MD, Helps SC, Field J, Hamilton-Bruce MA, Warming S, Manavis J, Vink R, Gronthos S, Koblar SA (2012) Human adult dental pulp stem cells enhance poststroke functional recovery through non-neural replacement mechanisms. Stem Cells Transl Med 1:177-187. CrossRef Medline

Li S, Hu GF (2012) Emerging role of angiogenin in stress response and cell survival under adverse conditions. J Cell Physiol 227:2822-2826. CrossRef Medline

Linnartz B, Neumann H (2013) Microglial activatory (immunoreceptor tyrosine-based activation motif)- and inhibitory (immunoreceptor tyrosine-based inhibition motif)-signaling receptors for recognition of the neuronal glycocalyx. Glia 61:37-46. CrossRef Medline

Little MC, Hurst RJ, Else KJ (2014) Dynamic changes in macrophage activation and proliferation during the development and resolution of intestinal inflammation. J Immunol 193:4684-4695. CrossRef Medline

Mackenzie F, Ruhrberg C (2012) Diverse roles for VEGF-A in the nervous system. Development 139:1371-1380. CrossRef Medline

Maina F, Klein R (1999) Hepatocyte growth factor, a versatile signal for developing neurons. Nat Neurosci 2:213-217. CrossRef Medline

Mantovani A, Biswas SK, Galdiero MR, Sica A, Locati M (2013) Macrophage plasticity and polarization in tissue repair and remodelling. J Pathol 229:176-185. CrossRef Medline

McWhorter FY, Wang T, Nguyen P, Chung T, Liu WF (2013) Modulation of macrophage phenotype by cell shape. Proc Natl Acad Sci U S A 110: 17253-17258. CrossRef Medline

Minor K, Tang X, Kahrilas G, Archibald SJ, Davies JE, Davies SJ (2008) 
Decorin promotes robust axon growth on inhibitory CSPGs and myelin via a direct effect on neurons. Neurobiol Dis 32:88-95. CrossRef Medline

Miron VE, Boyd A, Zhao JW, Yuen TJ, Ruckh JM, Shadrach JL, van Wijngaarden P, Wagers AJ, Williams A, Franklin RJ, ffrench-Constant C (2013) M2 microglia and macrophages drive oligodendrocyte differentiation during CNS remyelination. Nat Neurosci 16:1211-1218. CrossRef Medline

Miura M, Gronthos S, Zhao M, Lu B, Fisher LW, Robey PG, Shi S (2003) SHED: stem cells from human exfoliated deciduous teeth. Proc Natl Acad Sci U S A 100:5807-5812. CrossRef Medline

Miyagi T, Yamaguchi K (2012) Mammalian sialidases: physiological and pathological roles in cellular functions. Glycobiology 22:880-896. CrossRef Medline

Murray PJ, Allen JE, Biswas SK, Fisher EA, Gilroy DW, Goerdt S, Gordon S, Hamilton JA, Ivashkiv LB, Lawrence T, Locati M, Mantovani A, Martinez FO, Mege JL, Mosser DM, Natoli G, Saeij JP, Schultze JL, Shirey KA, Sica A, Suttles J, Udalova I, van Ginderachter JA, Vogel SN, Wynn TA (2014) Macrophage activation and polarization: nomenclature and experimental guidelines. Immunity 41:14-20. CrossRef Medline

Nakajima H, Uchida K, Guerrero AR, Watanabe S, Sugita D, Takeura N, Yoshida A, Long G, Wright KT, Johnson WE, Baba H (2012) Transplantation of mesenchymal stem cells promotes the alternative pathway of macrophage activation and functional recovery after spinal cord injury. J Neurotrauma 29:1614-1625. CrossRef Medline

Nauta AJ, Raaschou-Jensen N, Roos A, Daha MR, Madsen HO, BorriasEssers MC, Ryder LP, Koch C, Garred P (2003) Mannose-binding lectin engagement with late apoptotic and necrotic cells. Eur J Immunol 33: 2853-2863. CrossRef Medline

Németh K, Leelahavanichkul A, Yuen PS, Mayer B, Parmelee A, Doi K, Robey PG, Leelahavanichkul K, Koller BH, Brown JM, Hu X, Jelinek I, Star RA, Mezey E (2009) Bone marrow stromal cells attenuate sepsis via prostaglandin $\mathrm{E}(2)$-dependent reprogramming of host macrophages to increase their interleukin-10 production. Nat Med 15:42-49. CrossRef Medline

Ohtaki H, Ylostalo JH, Foraker JE, Robinson AP, Reger RL, Shioda S, Prockop DJ (2008) Stem/progenitor cells from bone marrow decrease neuronal death in global ischemia by modulation of inflammatory/immune responses. Proc Natl Acad Sci U S A 105:14638-14643. CrossRef Medline

Osada T, Watanabe M, Hasuo A, Imai M, Suyama K, Sakai D, Kawada H, Matsumae M, Mochida J (2010) Efficacy of the coadministration of granulocyte colony-stimulating factor and stem cell factor in the activation of intrinsic cells after spinal cord injury in mice. J Neurosurg Spine 13:516-523. CrossRef Medline

Ouyang W, Rutz S, Crellin NK, Valdez PA, Hymowitz SG (2011) Regulation and functions of the IL-10 family of cytokines in inflammation and disease. Annu Rev Immunol 29:71-109. CrossRef Medline

Pérez-Martinez L, Jaworski DM (2005) Tissue inhibitor of metalloproteinase-2 promotes neuronal differentiation by acting as an anti-mitogenic signal. J Neurosci 25:4917-4929. CrossRef Medline

Piltonen M, Planken A, Leskelä O, Myöhänen TT, Hänninen AL, Auvinen P, Alitalo K, Andressoo JO, Saarma M, Männistö PT (2011) Vascular endothelial growth factor $\mathrm{C}$ acts as a neurotrophic factor for dopamine neurons in vitro and in vivo. Neuroscience 192:550-563. CrossRef Medline

Pizzi MA, Crowe MJ (2006) Transplantation of fibroblasts that overexpress matrix metalloproteinase- 3 into the site of spinal cord injury in rats. J Neurotrauma 23:1750-1765. CrossRef Medline

Reimunde P, Quintana A, Castañón B, Casteleiro N, Vilarnovo Z, Otero A, Devesa A, Otero-Cepeda XL, Devesa J (2011) Effects of growth hormone $(\mathrm{GH})$ replacement and cognitive rehabilitation in patients with cognitive disorders after traumatic brain injury. Brain Inj 25:65-73. CrossRef Medline

Roca H, Varsos ZS, Sud S, Craig MJ, Ying C, Pienta KJ (2009) CCL2 and interleukin-6 promote survival of human $\mathrm{CD} 11 \mathrm{~b}+$ peripheral blood mononuclear cells and induce M2-type macrophage polarization. J Biol Chem 284:34342-34354. CrossRef Medline

Rowland JW, Hawryluk GWJ, Kwon B, Fehlings MG (2008) Current status of acute spinal cord injury pathophysiology and emerging therapies: promise on the horizon. Neurosurg Focus 25:E2. CrossRef Medline

Sakai K, Yamamoto A, Matsubara K, Nakamura S, Naruse M, Yamagata M, Sakamoto K, Tauchi R, Wakao N, Imagama S, Hibi H, Kadomatsu K, Ishiguro N, Ueda M (2012) Human dental pulp-derived stem cells promote locomotor recovery after complete transection of the rat spinal cord by multiple neuro-regenerative mechanisms. J Clin Invest 122:80-90. CrossRef Medline

Sakurai T (2012) The role of NrCAM in neural development and disordersbeyond a simple glue in the brain. Mol Cell Neurosci 49:351-363. CrossRef Medline

Schwab JM, Brechtel K, Mueller CA, Failli V, Kaps HP, Tuli SK, Schluesener HJ (2006) Experimental strategies to promote spinal cord regenerationan integrative perspective. Prog Neurobiol 78:91-116. CrossRef Medline

Shachar I, Karin N (2013) The dual roles of inflammatory cytokines and chemokines in the regulation of autoimmune diseases and their clinical implications. J Leukoc Biol 93:51-61. CrossRef Medline

Shechter R, London A, Varol C, Raposo C, Cusimano M, Yovel G, Rolls A, Mack M, Pluchino S, Martino G, Jung S, Schwartz M (2009) Infiltrating blood-derived macrophages are vital cells playing an anti-inflammatory role in recovery from spinal cord injury in mice. PLoS Med 6:e1000113. CrossRef Medline

Shin T, Ahn M, Moon C, Kim S, Sim KB (2013) Alternatively activated macrophages in spinal cord injury and remission: another mechanism for repair? Mol Neurobiol 47:1011-1019. CrossRef Medline

Silver J, Miller JH (2004) Regeneration beyond the glial scar. Nat Rev Neurosci 5:146-156. CrossRef Medline

Singer NG, Caplan AI (2011) Mesenchymal stem cells: mechanisms of inflammation. Annu Rev Pathol 6:457-478. CrossRef Medline

Snyder EY, Teng YD (2012) Stem cells and spinal cord repair. N Engl J Med 366:1940-1942. CrossRef Medline

Subramaniam S, Strelau J, Unsicker K (2003) Growth differentiation factor-15 prevents low potassium-induced cell death of cerebellar granule neurons by differential regulation of Akt and ERK pathways. J Biol Chem 278:8904-8912. CrossRef Medline

Taghipour Z, Karbalaie K, Kiani A, Niapour A, Bahramian H, Nasr-Esfahani MH, Baharvand H (2012) Transplantation of undifferentiated and induced human exfoliated deciduous teeth-derived stem cells promote functional recovery of rat spinal cord contusion injury model. Stem Cells Dev 21:1794-1802. CrossRef Medline

Tauchi R, Imagama S, Natori T, Ohgomori T, Muramoto A, Shinjo R, Matsuyama Y, Ishiguro N, Kadomatsu K (2012) The endogenous proteoglycan-degrading enzyme ADAMTS-4 promotes functional recovery after spinal cord injury. J Neuroinflammation 9:53. CrossRef Medline

Tsou CL, Peters W, Si Y, Slaymaker S, Aslanian AM, Weisberg SP, Mack M, Charo IF (2007) Critical roles for CCR2 and MCP-3 in monocyte mobilization from bone marrow and recruitment to inflammatory sites. J Clin Invest 117:902-909. CrossRef Medline

van Velthoven CT, Heijnen CJ, van Bel F, Kavelaars A (2011) Osteopontin enhances endogenous repair after neonatal hypoxic-ischemic brain injury. Stroke 42:2294-2301. CrossRef Medline

Wakao N, Imagama S, Zhang H, Tauchi R, Muramoto A, Natori T, Takeshita S, Ishiguro N, Matsuyama Y, Kadomatsu K (2011) Hyaluronan oligosaccharides promote functional recovery after spinal cord injury in rats. Neurosci Lett 488:299-304. CrossRef Medline

Wu XH, Yang SH, Duan DY, Cheng HH, Bao YT, Zhang Y (2007) Antiapoptotic effect of insulin in the control of cell death and neurologic deficit after acute spinal cord injury in rats. J Neurotrauma 24:1502-1512. CrossRef Medline

Yamagata M, Yamamoto A, Kako E, Kaneko N, Matsubara K, Sakai K, Sawamoto K, Ueda M (2013) Human dental pulp-derived stem cells protect against hypoxic-ischemic brain injury in neonatal mice. Stroke 44:551-554. CrossRef Medline

Yamamoto A, Sakai K, Matsubara K, Kano F, Ueda M (2014) Multifaceted neuro-regenerative activities of human dental pulp stem cells for functional recovery after spinal cord injury. Neurosci Res 78:16-20. CrossRef Medline

Yang YG, Jiang DM, Quan ZX, Ou YS (2009) Insulin with chondroitinase $\mathrm{ABC}$ treats the rat model of acute spinal cord injury. J Int Med Res 37: 1097-1107. CrossRef Medline

Zachary I (2005) Neuroprotective role of vascular endothelial growth factor: signalling mechanisms, biological function, and therapeutic potential. Neurosignals 14:207-221. CrossRef Medline

Zhang S, Xia YY, Lim HC, Tang FR, Feng ZW (2010) NCAM-mediated locomotor recovery from spinal cord contusion injury involves neuroprotection, axon regeneration, and synaptogenesis. Neurochem Int 56 : 919-929. CrossRef Medline 